\title{
Observations of Shoaling Nonlinear Internal Bores across the Central California Inner Shelf
}

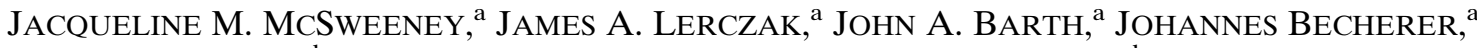 \\ John A. Colosi, ${ }^{\mathrm{b}}$ JenNifer A. MACKinnon, ${ }^{\mathrm{c}}$ JAMIE H. MACMAHAn, ${ }^{\mathrm{b}}$ JAMES N. Moum, \\ STEPHEN D. Pierce, ${ }^{\mathrm{a}}$ AND AMY F. WATERHOUSE ${ }^{\mathrm{c}}$ \\ ${ }^{\text {a }}$ College of Earth, Ocean, and Atmospheric Sciences, Oregon State University, Corvallis, Oregon \\ ${ }^{\mathrm{b}}$ Department of Oceanography, Naval Postgraduate School, Monterey Bay, California \\ ${ }^{\mathrm{c}}$ Scripps Institution of Oceanography, University of California, San Diego, La Jolla, California
}

(Manuscript received 21 May 2019, in final form 24 September 2019)

\begin{abstract}
We present observations of shoaling nonlinear internal bores off the coast of central California. The dataset includes 15 moorings deployed during September-October 2017 and cross-shore shipboard surveys. We describe the cross-shore structure and evolution of large-amplitude internal bores as they transit from $9 \mathrm{~km}$ (100-m depth) to $1 \mathrm{~km}$ offshore $(10 \mathrm{~m})$. We observe that two bores arrive each semidiurnal period, both propagating from the southwest; of the total, $72 \%$ are tracked to the $10-\mathrm{m}$ isobath. The bore speeds are subtidally modulated, but there is additional bore-to-bore speed variability that is unexplained by the upstream stratification. We quantify temporal and cross-shore variability of the waveguide (the background conditions through which bores propagate) by calculating the linear longwave nonrotating phase speed $c_{o}$ and using the nonlinearity coefficient of the Korteweg-de Vries equation $\alpha$ as a metric for stratification. Bore fronts are generally steeper when $\alpha$ is positive and are more rarefied when $\alpha$ is negative, and we observe the bore's leading edge to rarefy from a steep front when $\alpha$ is positive offshore and negative inshore. Highfrequency $\alpha$ fluctuations, such as those nearshore driven by wind relaxations, contribute to bore-to-bore variability of the cross-shore evolution during similar subtidal waveguide conditions. We compare observed bore speeds with $c_{o}$ and the rotating group velocities $c_{g}$, concluding that observed speeds are always faster than $c_{g}$ and are slower than $c_{o}$ at depths greater than $32 \mathrm{~m}$ and faster than $c_{o}$ at depths of less than $32 \mathrm{~m}$. The bores maintain a steady speed while transiting into shallower water, contrary to linear estimates that predict bores to slow.
\end{abstract}

\section{Introduction}

Coastal internal waves (IWs) have piqued scientific interest since the 1960s (Perry and Schimke 1965; Cairns 1967; Lee 1961), resulting in a growing number of observational and modeling studies. They have been observed worldwide, including Massachusetts Bay (Chereskin 1983; Scotti et al. 2008; Thomas et al. 2016), the South China Sea (Alford et al. 2010; Li and Farmer 2011), Southern and Central California (Lerczak et al. 2003; Walter et al. 2012; Colosi et al. 2018), the Australian northwest shelf (Holloway et al. 1997), the Oregon coast (Stanton and Ostrovsky 1998; Moum et al. 2003), and the New Jersey shelf (Shroyer et al. 2011). These waves contribute substantially to transport and mixing on continental shelves.

Corresponding author: Jacqueline McSweeney, jmcsweeney@ coas.oregonstate.edu
Coastal IW research has encompassed a broad range of topics, including the generation, evolution, and destruction of high-frequency IWs (also known as solitary waves or solitons), internal bores, and the internal tide. The internal tide is an IW packet that is generated by the barotropic tide, has a long cross-shore length scale of approximately $O(1-10 \mathrm{~km})$, and may include both bores and high-frequency IWs that are coevolving. There is ongoing research related to the interactions of bores and high-frequency IWs; however, this paper specifically focuses on the evolution of highly nonlinear, large-amplitude internal bores propagating across the shelf into shallower depths.

When the barotropic tide interacts with topography, such as the shelf break (Holloway et al. 1997) or a submarine bank (Lee and Beardsley 1974; Chereskin 1983; Scotti et al. 2007), it produces a large depression in the pycnocline. This depression wave propagates shoreward and evolves nonlinearly, with the leading edge steepening 
into a bore front (Lamb 1994; Scotti et al. 2007). Most observations indicate that one shoreward propagating bore is formed every semidiurnal $\left(M_{2}\right)$ period (Chereskin 1983; Holloway 1987; Ramp et al. 2004; Scotti et al. 2007; Alford et al. 2010), but a handful of observations include two bores each semidiurnal period (Lamb 1994; Shroyer et al. 2011). Since IWs facilitate significant cross-shelf exchange of energy and heat on the inner shelf, the presence of two $M_{2}$ bores likely has important dynamical and ecological impacts.

As an internal bore shoals, its evolution is influenced by its amplitude and the shelf stratification ahead of it (the upstream stratification). From the outer shelf to midshelf, an internal bore can propagate either as a single bore of depression or as an undular bore (Lee and Beardsley 1974; Chereskin 1983; Henyey and Hoering 1997; Apel 2003). As it transits into the inner shelf, the bore's evolution becomes strongly dependent on the upstream stratification (Helfrich et al. 1984; Vlasenko and Hutter 2002; Scotti et al. 2008). If the upstream pycnocline is above middepth, the bore's leading edge will continue to steepen and a sharp front will be maintained over the shoaling region. However, if the upstream pycnocline is near or below middepth, the bore's leading edge will rarefy, causing a decrease in the front steepness.

Several studies have used weakly nonlinear theory to describe the waveguide (the background conditions through which a bore propagates) by calculating the quadratic nonlinearity and dispersion coefficients $(\alpha$ and $\beta$, respectively) of the Korteweg-de Vries (KdV) equation (Helfrich et al. 1984; Holloway et al. 1997; Vlasenko and Stashchuk 2007; Shroyer et al. 2009). These studies draw attention to an important transition region during shoaling — the "critical depth"- - where $\alpha$ changes sign, solitary IWs switch polarity (Shroyer et al. 2009), and a bore's leading edge may scatter into high-frequency waves (Helfrich et al. 1984). For a two-layer system, $\alpha$ 's sign suggests whether the pycnocline is above $(\alpha=+)$, at ( $\alpha=0$; critical depth), or below $(\alpha=-)$ middepth (Grimshaw et al. 1997). An internal bore's cross-shore evolution depends on both 1) the upstream stratification, which can be described by $\alpha$ and may have local, highfrequency variability (Holloway et al. 1997; Vlasenko and Stashchuk 2007), and 2) the location of the critical depth, which is not fixed. High-frequency fluctuations of $\alpha$, such as those caused by the passage of an internal tide, can be especially impactful since nonlinearity is the dominant factor controlling a shoaling bore's evolution (Scotti et al. 2008) and determining whether a bore will break or develop a trailing packet of dispersive waves (Vlasenko and Hutter 2002).

While weakly nonlinear theory provides valuable insight into shoaling IWs, most coastal IWs are highly nonlinear and thus our understanding of them necessitates models that are either fully nonlinear or incorporate higher-order nonlinearity. The extended KdV equation, for example, includes a cubic nonlinearity term that becomes especially important to understanding a wave's evolution when crossing the critical depth (Lamb and Yan 1996; Grimshaw et al. 1997, 2002; Lamb and WarnVarnas 2015). Fully nonlinear models that include rotation have also demonstrated that both shoaling and rotation contribute to nonlinearities associated with the decay and regeneration of wave packets (Helfrich 2007; Stastna et al. 2009; Grimshaw et al. 2014). This paper focuses on observational analyses and a comparison to linear bore speeds, but we lean on findings from numerical studies to support our interpretation of these complicated, nonlinear shoaling dynamics.

The evolution of an internal bore across the shelf and the location/isobath at which it breaks has important implications for mixing and the cross-shelf exchange of water properties, energy, and biota. For example, the shape of a bore's front during shoaling will determine whether mixing is generated on the main pycnocline or near the bed (Moum et al. 2003; Shroyer et al. 2010). Additionally, a bore's amplitude, speed, and evolving frontal shape will modify the transport of particulates and nutrients, thus affecting the distribution and recruitment of various littoral larval species (Pineda 1991, 1999; Scotti and Pineda 2004). These dynamical and ecological impacts provide further motivation to understand drivers of waveguide variability and their influence on how internal bores evolve.

The 2017 Inner Shelf Dynamics Experiment (Lerczak et al. 2019) provides a unique and well-resolved dataset to study the propagation and evolution of internal bores from the mid ( $\sim 100-\mathrm{m}$ depth) to inner $(\sim 10 \mathrm{~m})$ shelf of central California. Focusing on a region with roughly alongshore uniform bathymetry that shallows linearly to the coast, we quantify temporal (subtidal and boreto-bore) and cross-shore variations in the waveguide by calculating $\alpha$ at 15 moorings. We also compare measured bore speeds to estimates of the linear longwave nonrotating phase speed and rotating group velocities, illustrating that bores do not slow over the shoaling region as predicted. We qualitatively describe how waveguide variations impact bore propagation, demonstrating that spatiotemporal variability in stratification strongly controls how bores evolve when transiting into shallower water.

\section{Methods}

We utilize a subset of the Inner Shelf Dynamics Experiment data (Lerczak et al. 2019) to focus on the 
region offshore of Oceano (Fig. 1), north of Point Sal, California. The topography there is relatively planar, making the region well suited for comparisons with two-dimensional theory.

\section{a. Data collection and processing}

We analyze data from 15 moorings deployed in 100-9 m depth from 6 September 2017 to 31 October 2017 (Fig. 1). Several moorings were serviced 5-8 October 2017.

Each lander mooring (Fig. 1: "A") had a tripod with an upward-looking ADCP that was connected to a surface buoy. These had temperature sensors on the tripod and surface buoy but no instrumentation mid-water column. The string moorings (Fig. 1: "T") had primarily temperature loggers at roughly $1-2-\mathrm{m}$ increments and were kept taut by two subsurface buoys ( $\sim 2$ and $5 \mathrm{~m}$ below the surface). Using pressure sensors distributed vertically on the MS100 and OC50 moorings, we estimate that mooring tilt contributed to a vertical displacement of $2-15 \mathrm{~cm}$ over a tidal cycle. For locations with both a lander and string mooring, the two were deployed with a horizontal separation of $\sim 1$ water depth.

Temperature was the dominant control on density during the experiment, with salinity at the OC50 ranging from 33.25 to $33.58 \mathrm{~g} \mathrm{~kg}^{-1}$ over the entire observational period. Thus, density is calculated assuming a constant salinity of $33.43 \mathrm{~g} \mathrm{~kg}^{-1}$ at all moorings.

Data processing included extrapolation of velocity, temperature, and density data to the surface and bed. Velocity data is missing in the $\sim 10 \%$ top part of the water column because of sidelobe contamination and from the bed to $\sim 1.5 \mathrm{~m}$ above the bed (mab). Temperature loggers were deployed from $\sim 0.5 \mathrm{mab}$ and to $\sim 0.5-2 \mathrm{~m}$ below the surface. Both velocity and temperature measurements were extrapolated using a quadratic polynomial regression and assuming no shear at the boundaries. After extrapolation, temporal gaps of $<5$ min were filled using linear interpolation. All temperature and velocity data were averaged to 1-min resolution.

Lamb (2002) demonstrated that properties of largeamplitude IWs, such as those observed here, are sensitive to near-surface stratification. Given the lack of surface data, wave properties estimated from stratification may be sensitive to the extrapolation methods. A few moorings had surface-following temperature sensors, so we used these to confirm that calculated wave properties were minimally influenced by our surface extrapolation methods.

Shipboard surveys were conducted from the R/V Oceanus 6-17 September 2017. We present six crossshore transects along the southern-Oceano mooring line on September 9th that captured the cross-shore propagation of an internal bore (Fig. 1). During this survey, the ship steamed at $\sim 3 \mathrm{kt}\left(1 \mathrm{kt} \approx 0.51 \mathrm{~m} \mathrm{~s}^{-1}\right)$ while towyoing a CTD package, yielding a resolution of $\sim 200 \mathrm{~m}$ horizontally and $\sim 0.1 \mathrm{~m}$ vertically. Shipboard velocity data collected from a downward-looking polemounted $600-\mathrm{kHz}$ ADCP with 1-m bins were ensemble averaged to $1 \mathrm{~min}$.

Survey transects were converted to cross-shore distance using a shoreline reference (Fig. 1, small red dot). Temperature measurements were interpolated to this coordinate system using a 2D-LOESS filter ("locally estimated scatterplot smoothing") with decorrelation scales of 250 (horizontal) and $0.25 \mathrm{~m}$ (vertical). Velocity data were transformed to a northeast reference frame and used to identify the bore fronts for speed estimates (section 3a). The 1-min-averaged velocity data were then further smoothed using the same 2D-LOESS filter.

\section{b. Data analysis}

\section{1) QUANTIFYING BACKGROUND STRATIFICATION}

Inner shelf stratification is influenced by interacting processes on a broad range of spatiotemporal scales, including mesoscale/submesoscale eddies and winds. To study how stratification variability influences internal bores, it is necessary to identify the background stratification through which the bores propagate. However, this is challenging because internal bores themselves, which are persistently present on the shelf, significantly modify shelf stratification. It is not obvious how to objectively define the background stratification, and we find that a simple, time-averaged density field is not representative of the environment that IWs actually encounter. To address these nuances, we calculate the background density in two ways and compare their influences.

The first method of estimating background density, termed "sorted density" onward, focuses on capturing subtidal variability at each mooring. Following a method similar to that used by Winters et al. (1995), we sort all density measurements, uniformly spaced in depth, within $24.84 \mathrm{~h}$ ( 2 times the $M_{2}$ period) by increasing value, and scale this density profile to the total depth. This is done for the entire time series with a 6-h moving window. This method assumes that IWs are simply displacing isopycnals, thus minimizing the influence of IWs and focusing on the modulation of stratification by subtidal processes.

Our second estimate, termed "pre-arrival density," describes the local stratification just prior to a bore arrival. Using arrival times [section $2 \mathrm{~b}(2)]$, we compute the 30-min average density profile before each bore's arrival.

We use these two density products to additionally calculate the quadratic nonlinearity $\operatorname{KdV}$ coefficient $\alpha$, 


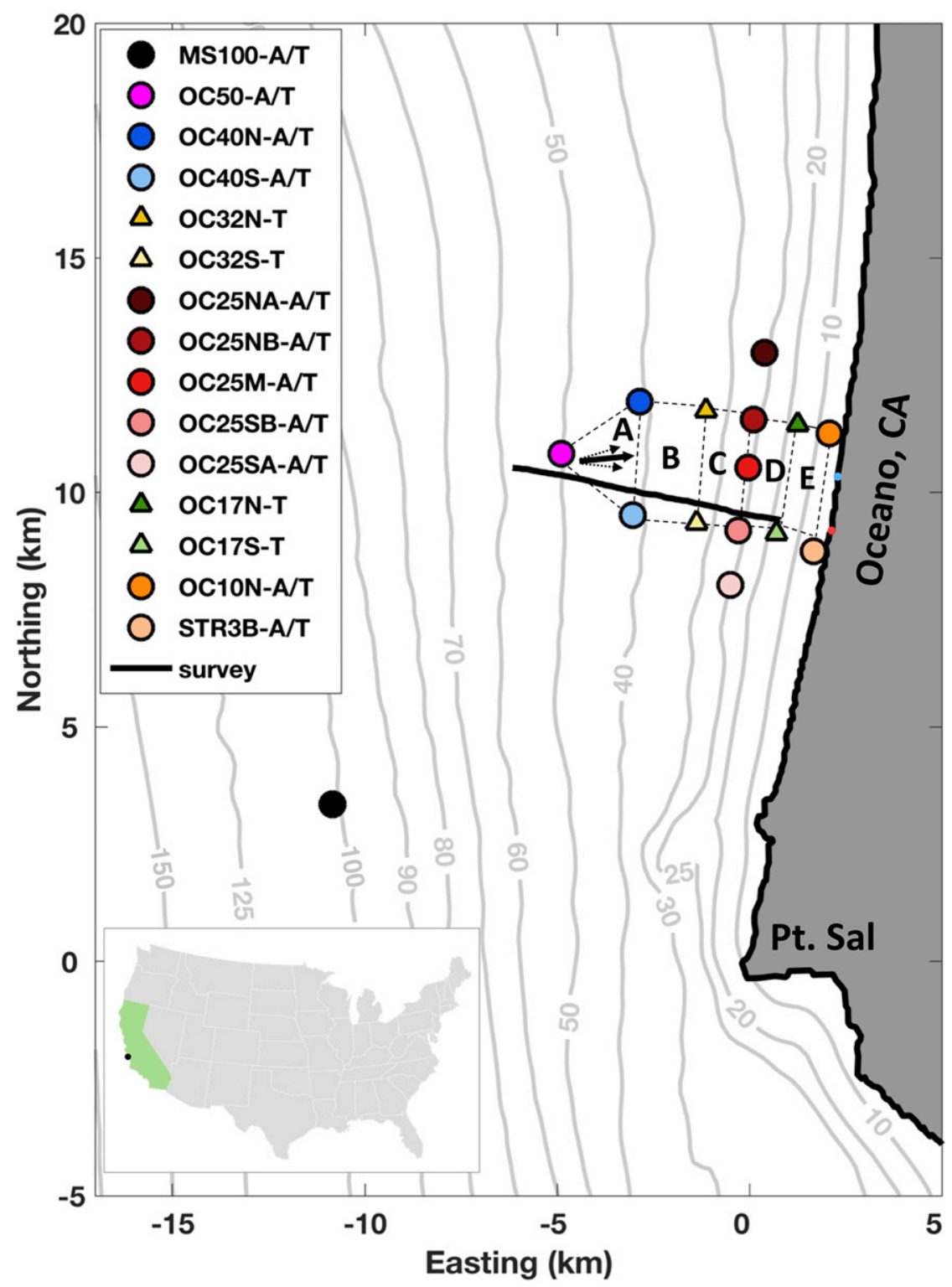

FIG. 1. Map of the 15 moorings used in this analysis with bathymetry contoured in light gray. The site location is offshore of Oceano, and the east-north coordinate system is centered on the tip of Point Sal. The mooring names are coded such that the first two or three letters indicate the broader location (MS = mid shelf, OC $=$ Oceano inner shelf, and STR $=$ nearshore), the following numbers indicate the water depth, and the letters at the end indicate the type of mooring design ( $\mathrm{A}=$ lander with upward-looking $\mathrm{ADCP} ; \mathrm{T}=$ string mooring with temperature sensors spaced vertically every $\sim 1-2 \mathrm{~m}$ ). For the moorings on the $25-\mathrm{m}$ isobath, they are labeled from north to south respectively as "NA," "NB," "M," "SB," and "SA." Six cross-shore transects with a towed CTD were conducted from the R/V Oceanus on 9 Sep 2017 (thick black line). Dashed triangles and rectangles (labeled with black letters A-E) denote the groups of moorings used for the speed and angle calculations discussed in section $2 b(3)$. The solid black arrow shows the mean propagation direction of bores at triangle A (Fig. 13, below), and the dashed arrows denote \pm 1 standard deviation (detailed in Table 2). The red and blue dot on the coast denote the coastline location for Figs. 3 and 14, described below. 
TABLE 1. Information about the internal bores tracked through the Oceano mooring array. For the number of hours between subsequent bores, this includes all times (even though Fig. 6 includes only cases that are $<24 \mathrm{~h}$ ).

\begin{tabular}{|c|c|c|c|c|c|c|c|}
\hline Mooring & $\begin{array}{c}\text { No. of } \\
\text { bores } \\
\text { identified }\end{array}$ & $\begin{array}{c}\text { Identified bores/ } \\
\text { observational } \\
\text { days }\end{array}$ & $\begin{array}{c}\text { Mean no. of hours } \\
\text { between } \\
\text { subsequent bores }\end{array}$ & $\begin{array}{l}\text { Std dev of mean no. } \\
\text { of hours between } \\
\text { subsequent bores }\end{array}$ & $\begin{array}{c}\text { No. of } \\
\text { tracked } \\
\text { bores }\end{array}$ & $\begin{array}{c}\text { Tracked bores } \\
\text { with } \pm 15 \text {-min } \\
\text { cutoff flag }\end{array}$ & $\begin{array}{c}\text { Tracked bores } \\
\text { with } \pm 7.5 \text {-min } \\
\text { cutoff flag }\end{array}$ \\
\hline MS100 & 178 & 3.34 & 7.08 & 3.21 & 148 & 102 & 67 \\
\hline OC50 & 158 & 3.11 & 7.90 & 3.59 & 148 & 105 & 82 \\
\hline OC40N & 141 & 2.68 & 8.39 & 4.56 & 139 & 79 & 64 \\
\hline OC40S & 149 & 2.91 & 7.93 & 3.60 & 139 & 93 & 67 \\
\hline OC $32 \mathrm{~N}$ & 142 & 2.55 & 8.75 & 3.90 & 138 & 65 & 46 \\
\hline OC $32 \mathrm{~S}$ & 146 & 2.70 & 8.65 & 4.24 & 132 & 79 & 56 \\
\hline OC25NA & 132 & 2.39 & 9.03 & 4.14 & 131 & 69 & 38 \\
\hline OC25NB & 133 & 2.56 & 8.97 & 4.02 & 131 & 63 & 46 \\
\hline OC25M & 130 & 2.50 & 8.98 & 3.95 & 130 & 70 & 49 \\
\hline OC25SB & 126 & 2.47 & 9.05 & 4.16 & 126 & 64 & 50 \\
\hline OC25SA & 129 & 2.49 & 8.47 & 3.85 & 129 & 73 & 55 \\
\hline OC17N & 118 & 2.14 & 9.56 & 4.27 & 116 & 60 & 45 \\
\hline OC17S & 113 & 2.05 & 9.58 & 4.31 & 111 & 61 & 42 \\
\hline OC10N & 64 & 2.07 & 9.89 & 5.70 & 64 & 31 & 19 \\
\hline STR3B-9 & 69 & 1.58 & 9.81 & 5.36 & 69 & 33 & 17 \\
\hline
\end{tabular}

which we utilize as a metric of stratification for this analysis. The $\mathrm{KdV}$ equation, which is described thoroughly in Grimshaw et al. (2004), relates changes in the vertical displacement of the pycnocline $\eta$ to nonlinearity and dispersion in the absence of rotation:

$$
\frac{\partial \eta}{\partial t}+\left(c_{o}+\alpha \eta\right) \frac{\partial \eta}{\partial x}+\beta \frac{\partial^{3} \eta}{\partial x^{3}}=0
$$

where $c_{o}$ is the mode-one longwave linear phase speed, $\beta$ is the dispersion coefficient, $x$ is the cross-shore horizontal coordinate, $t$ is time, and $\eta$ varies in both $x$ and $t$. In the absence of background shear, the nonlinearity and dispersion coefficients are

$$
\alpha=\frac{3 \int_{-H}^{0} c_{o}^{2}\left(\frac{\partial \phi}{\partial z}\right)^{3} d z}{2 \int_{-H}^{0} c_{o}\left(\frac{\partial \phi}{\partial z}\right)^{2} d z} \text { and } \beta=\frac{\int_{-H}^{0} c_{o}^{2} \phi^{2} d z}{2 \int_{-H}^{0} c_{o}\left(\frac{\partial \phi}{\partial z}\right)^{2} d z}
$$

where $\phi$ is the vertical structure function, $z$ denotes the vertical coordinate system, and $H$ is the total water depth.

It is well known that background shear can significantly influence the propagation and evolution of a shoaling bore (Lee and Beardsley 1974; Stastna and Lamb 2002), but we intentionally exclude shear in our estimates of $\alpha$ and $c_{o}$ to focus on the influences of stratification. This decision is motivated by our finding that $\alpha$ and $c_{o}$ estimates are sensitive to the definition of background shear and, like the background stratification, this choice is not obvious. While shear and stratification both play a role in modulating IW characteristics, their relative influences cannot be delineated in a simple way. Other IW studies have excluded shear to strategically elucidate effects of stratification (Holloway et al. 1997; Scotti et al. 2007), and we similarly do so with the intention of discussing shear impacts in a follow up paper.

\section{2) IDENTIFYING INTERNAL BORE ARRIVALS}

To discuss the evolution of shoaling internal bores, we must track a bore as it transits through the mooring array. We do so using the following methods.

First, we identify all bore arrivals at each mooring using a filtered pycnocline displacement. We select an isopycnal that qualitatively tracks the pycnocline and calculate its displacement $Z_{p}$ relative to its background depth from the sorted density profile. Because the background stratification evolves over the 2 months, a single isopycnal is not representative of the pycnocline for the whole time series. Thus, we conduct this analysis with three isopycnals and choose the most representative of the pycnocline at a given time. To identify an arrival, we bandpass filter $(0.5-16 \mathrm{~h})$ the isopycnal displacements and find local minima of $d Z_{p} / d t$. This approach targets instances in the semidiurnal period in which the pycnocline is rapidly displaced downward. Stratification and IW conditions impact the magnitude/rate of displacement, so we cannot place thresholds on how far/fast the pycnocline must be depressed to qualify as a bore. Thus, local minima are identified automatically and we use the 1-min temperature and eastward semidiurnal velocity data to manually confirm that the minima coincide with a bore's passage. From this step, we quantify the number of bores observed at each mooring (Table 1, column 2). 
TABLE 2. The number of estimates of speed/direction from bore arrivals, the mean speed $\left(\mathrm{cm} \mathrm{s}^{-1}\right)$, the standard deviation in speed $\left(\mathrm{cm} \mathrm{s}^{-1}\right.$ ), the propagation angle (degrees relative to east; positive is propagating to the north), and standard deviation of the angle for triangles A-E shown in Fig. 1. For all columns, the estimates correspond to bores flagged by the \pm 7.5 -min (left of the slash) and \pm 15 -min (right of the slash) certainty thresholds [section $2 \mathrm{~b}(2)$ ].

\begin{tabular}{cccccc}
\hline \hline & $\begin{array}{c}\text { No. } \\
\text { estimates } \\
\text { Triangle }\end{array}$ & $\begin{array}{c}\text { Mean } \\
\text { speed } \\
\left(\mathrm{cm} \mathrm{s}^{-1}\right)\end{array}$ & $\begin{array}{c}\text { Std dev } \\
\left(\mathrm{cm} \mathrm{s}^{-1}\right)\end{array}$ & $\begin{array}{c}\text { Mean } \\
\text { angle } \\
\left({ }^{\circ} ; 0^{\circ} \text { is }\right. \\
\text { east })\end{array}$ & $\begin{array}{c}\text { Std dev } \\
\text { of angle } \\
\left({ }^{\circ}\right)\end{array}$ \\
\hline A & $32 / 53$ & $20.6 / 21.1$ & $4.6 / 5.2$ & $5.1 / 6.4$ & $11.9 / 13.0$ \\
B & $39 / 65$ & $18.3 / 18.4$ & $4.0 / 4.1$ & $4.3 / 5.2$ & $13.2 / 13.6$ \\
C & $37 / 66$ & $16.5 / 16.6$ & $4.8 / 5.8$ & $2.5 / 1.2$ & $10.0 / 12.4$ \\
D & $33 / 48$ & $16.6 / 16.2$ & $6.2 / 5.8$ & $1.8 / 0.4$ & $10.9 / 12.0$ \\
E & $15 / 30$ & $14.4 / 13.1$ & $4.1 / 4.7$ & $-4.4 /-5.8$ & $10.0 / 9.5$ \\
\hline
\end{tabular}

The second step is to track each bore as it transits through the array. This involves comparing the arrival times at neighboring moorings over the period a shoreward-propagating wave would arrive (assuming $0.2-0.7 \mathrm{~m} \mathrm{~s}^{-1}$ speeds) and tracking specific features of both the bore and high-frequency IWs using the 1-min temperature data, bandpassed ( 3 min to $16 \mathrm{~h}$ ) eastward velocities, and $0.5-16-\mathrm{h}$ pycnocline displacements. This step-2 product, termed "tracked bores," includes 148 bores at MS100, the majority of which are observable to shore (Table 1, column 6).

The final step is to flag tracked bores by the certainty associated with their arrival times (Table 1, columns 7 and 8). Informed by an analysis of the error in speed estimates associated with arrival time uncertainty [section $2 b(4)$ ], we select certainty thresholds of \pm 7.5 and $\pm 15 \mathrm{~min}$. For example, a sharp bore with a pycnocline displacement of $25 \mathrm{~m}$ within $2 \mathrm{~min}$ would be positively flagged for the \pm 7.5 -min threshold. However, a bore with a gradually sloped leading edge that displaces the pycnocline $30 \mathrm{~m}$ over $25 \mathrm{~min}$ would be flagged only under the \pm 15 -min threshold. Note that the threshold is \pm minutes from a centered arrival time, so the window of certainty is double the threshold value.

Bores are much easier to track when the leading edge is steep (compared to when it is more rarefied). Thus, steps 1 and 3 likely contribute to an underestimation of the bores with gently sloped fronts.

\section{3) CAlculation of BORE SPEED AND DIRECTION}

We estimate the propagation direction and speed of each bore using arrival times at various mooring groups, following Scotti et al. (2005) and Thomas et al. (2016). This method assumes that a bore propagates through a mooring group as a straight linear feature with constant speed and direction. Speed and direction are estimated by minimizing the root-mean-square difference in observed arrival times at each location and the arrival time predicted for a particular speed/direction.

Mooring groups include both triangles and rectangles (Fig. 1). For example, triangle A consists of OC50, OC40N, and OC40S, yielding a speed/angle midway between the 50- and 40-m isobaths, and square B uses OC40N, OC40S, OC $32 \mathrm{~N}$, and OC32S to yield estimates between the 32 and $40 \mathrm{~m}$. For the rectangles, we average the speeds estimates from each possible triangle. This permits an estimate when a bore is observed at only three moorings, increasing the number of estimates. We compute speeds using only bores flagged by the $+/ 15$-min certainty, so there are fewer speed estimates (Table 2) than tracked bores (Table 1).

We then calculate linear speeds from both density products using the following eigenvalue problem:

$$
\begin{aligned}
\frac{\partial^{2} \phi}{\partial z^{2}}+\frac{1}{c_{o}^{2}} \frac{N^{2}}{\left(1-\frac{f}{\omega}\right)} \phi & =0, \\
c_{o} & =\omega / k, \text { and } \\
c_{g} & =\partial \omega / \partial k,
\end{aligned}
$$

where $N^{2}$ is the squared buoyancy frequency, $\omega$ is frequency, $f$ is the Coriolis parameter, and $k$ is the wavenumber. Given our decision to exclude shear in this analysis [section $2 \mathrm{~b}(1)]$, Eq. (3) is for a case without background current. We calculate $c_{o}$ for the nonrotating case $(f=0)$ and the group velocities $c_{g}$ for the rotating case with $\omega=12.42 \mathrm{~h}$. For the remainder of the paper, $c_{o}$ denotes the nonrotating phase speed.

\section{4) ESTIMATING ERROR IN BORE SPEED/DIRECTION CALCULATIONS}

To determine the error associated with the speed estimates from the triangulation method, we conduct an error analysis using synthetic IWs of known speed and direction. We run eight cases-four for both triangle $\mathrm{A}$ and $\mathrm{D}$, with waves speeds of $0.1,0.15,0.2$, and $0.25 \mathrm{~m} \mathrm{~s}^{-1}$ - and each case includes 10000 synthetic waves (Fig. 2). For each wave, the propagation direction is assigned randomly and random error scaled by a standard deviation ranging from 0 to $22.5 \mathrm{~min}$ is introduced to the arrival time estimates. Estimates of speed/direction from the triangulation method are compared with known values. We conclude that speed estimates are more accurate offshore (triangle A) than nearshore (D) and improve as the waves slow down. For arrival times with a certainty of $\pm 7.5 \mathrm{~min}$, the speed estimate of a $0.25 \mathrm{~m} \mathrm{~s}^{-1}$ bore at triangle $\mathrm{A}$ is within 

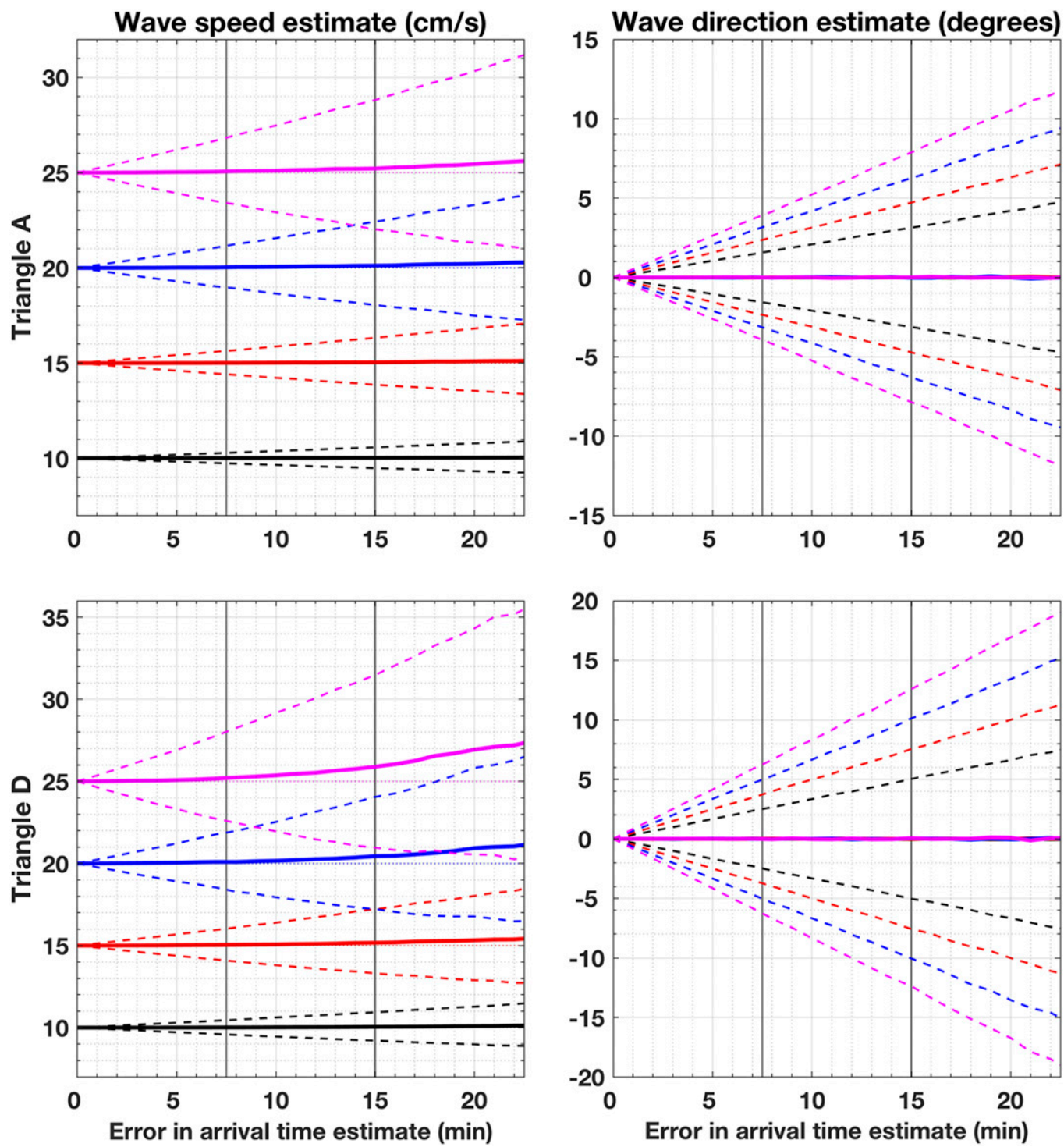

FIG. 2. (left) Wave speed estimate $\left(\mathrm{cm} \mathrm{s}^{-1}\right)$ from 10000 synthetic waves of known speeds and angle as a function of the error in arrival time ( $\mathrm{min}$ ) for (top) triangle A and (bottom) rectangle D shown in Fig. 1. Four wave speed cases were run-10,15, 20, and $25 \mathrm{~cm} \mathrm{~s}^{-1}$ — distinguished by black, red, blue, and magenta, respectively. Solid lines show the average value; dashed lines show $95 \%$ confidence limits. The vertical lines indicates the \pm 7.5 - and $+/ 15$-min threshold cutoffs for step 3 of bore identification [section $2 b(2)]$. (right) As in the left panels, but for wave direction estimate $\left({ }^{\circ}\right)$.

$0.035 \mathrm{~m} \mathrm{~s}^{-1}$ of the true speed and the wave direction is within $8^{\circ}$. Comparatively, a bore of the same speed with a certainty $+/ 15 \mathrm{~min}$ would have a speed/angle estimate that is within $0.07 \mathrm{~m} \mathrm{~s}^{-1}$ and $16^{\circ}$ of the true values.

\section{Results}

\section{a. The cross-shelf structure of the internal bores}

During the 7-h ship survey, we track a large-amplitude internal bore from $7.7 \mathrm{~km}$ (51.6-m depth) to $2.2 \mathrm{~km}$ (24.5-m depth) offshore (Fig. 3). The bore front remains sharp during the entire transit to shore. If we consider the bore to be two-layered and the $13^{\circ} \mathrm{C}$ isotherm to be a proxy for the pycnocline boundary, we can estimate the bore's amplitude relative to the total water depth (Table 3). Notably, the bore's amplitude is roughly half the water depth across the entire transect.

We estimate the bore speed from the distance traveled between front passages (Fig. 3 black text). Errors in this calculation are estimated by adding $\pm 2 \mathrm{~min}$ of error to the passage times. For example, the error for the speed between $t=0$ and $t=1.3 \mathrm{~h}$ is estimated from the difference 
Eastward Velocity and Temperature at Mid-Oceano Cross Shelf Transect Observed via R/V Oceanus
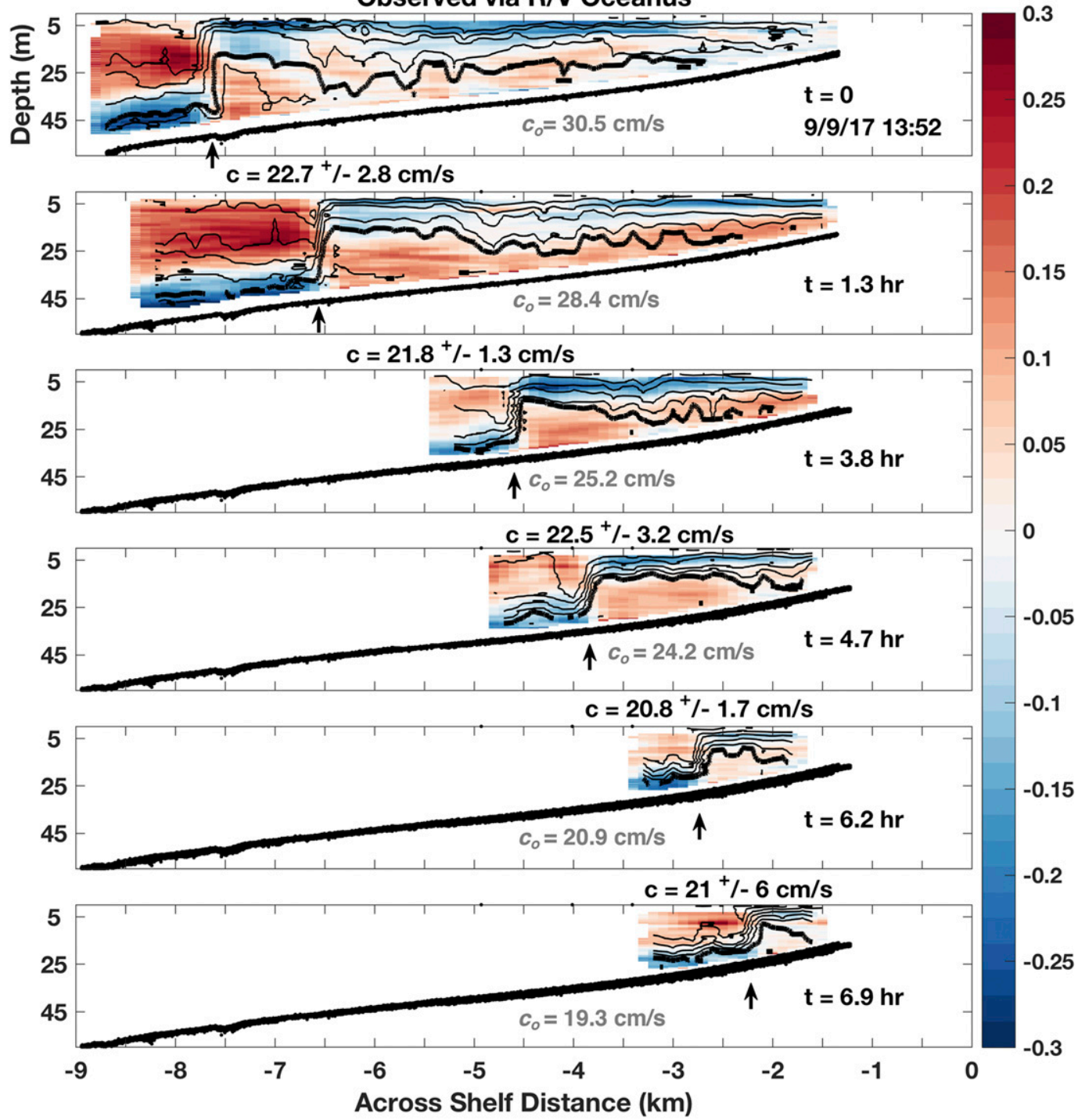

FIG. 3. Eastward velocity (colored, with positive values toward east), with $1^{\circ} \mathrm{C}$ temperature isotherms contoured (the boldface contour denotes the $13^{\circ} \mathrm{C}$ isotherm) from towed surveys along the course shown in Fig. 1. The thick black line denotes the bed depth from the ship's echosounder. Each panel shows a separate transect, with time progressing from top to bottom in the figure. The timestamp in each panel corresponds to the passage of the bore front, indicated with a black arrow, and counting from $t=0$ (1352 UTC 9 Sep 2017). The across-shelf distance is measured from the nearest location to the coastline if the transect path were to continue and intersect the shore (red dot in Fig. 1). The bore speeds estimated from distance traveled between bore passages are noted between the respective panels along with error estimates. The nonrotating longwave linear phase speeds $c_{o}$ estimated at the time/location of bore passage estimated from nearby moorings are shown in gray in each panel.

between the speeds calculated from time/distance measurements at $t_{0}$ and $t_{1.3 \mathrm{~h}}$ and from those at $\left(t_{0}-2 \mathrm{~min}\right)$ and $\left(t_{1.3 \mathrm{~h}}+2 \mathrm{~min}\right)$. The bore remains a fairly constant speed as it propagates to shore. In contrast, the estimate of $c_{o}$ estimated from the sorted density from nearby moorings (Fig. 3, gray text) predicts the bore to significantly slow over this shoaling region.
Considering each cross section to be a "snapshot" of the bore, the conditions prior to the bore arrival are characterized by offshore flow in the stratified surface layer compensated by shoreward flow at depth. There is a sharp depression of the pycnocline at the bore's leading edge followed strong onshore velocities at the surface and offshore velocities in the lower layer. The currents 
TABLE 3. The estimation of the bore's amplitude from Fig. 3, where $\Delta H$ is the vertical pycnocline displacement and $H$ is the total water depth, using the $13^{\circ}$ isotherm as a proxy for the pycnocline.

\begin{tabular}{cccc}
\hline \hline Time (h) & $\Delta H$ & $H$ & $\Delta H / H$ \\
\hline 0 & 23.7 & 51.6 & 0.46 \\
1.3 & 22.0 & 45.9 & 0.48 \\
3.8 & 17.2 & 36.7 & 0.47 \\
4.7 & 16.7 & 35.1 & 0.48 \\
6.2 & 11.4 & 28.0 & 0.41 \\
6.9 & 11.5 & 24.5 & 0.47 \\
\hline
\end{tabular}

associated with the bore weaken as the bore transits into shallower water.

We compare the survey view of the bore (Fig. 3) to observations from the southern cross-shore mooring transect (Fig. 4). Similarly, we observe a sharp bore front (Fig. 4, green triangles) that can be tracked from the $100-\mathrm{m}$ isobath to $9 \mathrm{~m}$ and depresses the pycnocline by roughly half the water column depth at all locations (except MS100). After the front passage, there is a surface, shoreward current compensated by offshore flow at depth. These currents are weaker inshore compared to offshore, consistent with the survey data. Observed bore speeds corroborate that the bore maintains a steady speed while shoaling. These time series also offer insight into the bore's high-frequency structure, which is not captured by the ship survey. For example, there are highfrequency elevation waves following the bore front at OC32S that have mostly disappeared by OC25SB.

\section{b. Observation of two internal bores within a semidiurnal period}

Bores transiting shoreward through the mooring array are evident in a 2-day time series of eastward velocity and temperature from the northern cross-shore mooring transect (Fig. 5). Focusing on MS100, we observe a bore arrival at the $100-\mathrm{m}$ isobath roughly every $6 \mathrm{~h}$ (nine bores over the 52-h period), all of which are trackable to shore.

Over the observational period that includes data from OC10N, 86 bores are observed at the 100- and 50-m isobaths. Ninety percent of these can be tracked to the $25-\mathrm{m}$ isobath, $81 \%$ can be tracked to the $17-\mathrm{m}$ isobath, and $72 \%$ can be tracked to the $10-\mathrm{m}$ isobath. However, if we consider only arrivals that meet the \pm 15 -min certainty threshold, $62 \%$ are trackable to $25 \mathrm{~m}, 55 \%$ are trackable to $17 \mathrm{~m}$, and $45 \%$ are trackable to $10 \mathrm{~m}$. Bores onshore of the $25-\mathrm{m}$ isobath are harder to identify because of the evolution of the bores' leading edge, and thus this estimate of bores that make it to shore is likely an underestimate.

We plot histograms of the number of hours between subsequent bores across the northern shoaling region, excluding cases in which $\Delta t>24 \mathrm{~h}$ (Fig. 6). These histograms confirm a peak at $\sim 6-7 \mathrm{~h}$ for all moorings, though the peaks are broader at moorings shallower than $40 \mathrm{~m}$. This suggests that there are times at which bores do not propagate all the way to shore and other times that two bores within a semidiurnal period are observed at the inshore locations.

The arrival of two bores each semidiurnal period is a surprising finding (section $4 \mathrm{a}$ ), but given this observation, we use it to estimate the maximum number of expected bores. If two bores arrived every semidiurnal period for 53 days (the observational period), 212 bores would be expected. Thus, we observe $84 \%$ of the maximum number of potential bores at MS100.

\section{c. Stratification variability}

To discuss spatiotemporal variability of the waveguide, we consider the upstream stratification conditions at the northern cross-shore mooring line. We compare the subtidal and pre-arrival density fields, as well as their corresponding $\alpha$ estimates.

Time series of sorted densities illustrate that the stratification conditions had considerable subtidal variability and across-shore structure during the observational period (Fig. 7). In early/mid-September, warm surface temperatures $\sim O\left(17^{\circ} \mathrm{C}\right.$ midshelf to $18.5^{\circ} \mathrm{C}$ inner shelf $)$ contributed to a relatively strong vertical stratification and horizontal cross-shore density gradient. For example, on 13 September the surface waters were more dense at OC40N than at both MS100 and OC17N, and the pycnocline was well above middepth offshore at MS100 but less defined inshore at OC17N. Comparatively, in late September/early October vertical stratification weakened, the pycnocline was less defined, and the horizontal cross-shore density gradients were less pronounced.

The subtidal stratification does not capture the specific stratification an individual bore propagates through (Fig. 7), especially since bores travel through the region roughly every $6 \mathrm{~h}$ and influence the stratification ahead of the next bore. To assess the importance of local upstream stratification, we compare the sorted and prearrival densities at OC50 (Fig. 8). The subtidal features are qualitatively similar in both density products, but the pre-arrival data illustrate higher-frequency variability in the vertical density structure, which impacts $\alpha$ and $c_{o}$. For example, during early/mid-September when stratification is strong, there is a heaving of the isopycnals $\sim O(10 \mathrm{~m}), 1 / 5$ of the water depth, on time scales shorter than a day that cause relatively large fluctuations in $\alpha$.

To understand the broader context of the observed subtidal stratification variability, we present a time series of $\alpha$ estimated from the sorted density at the northern 

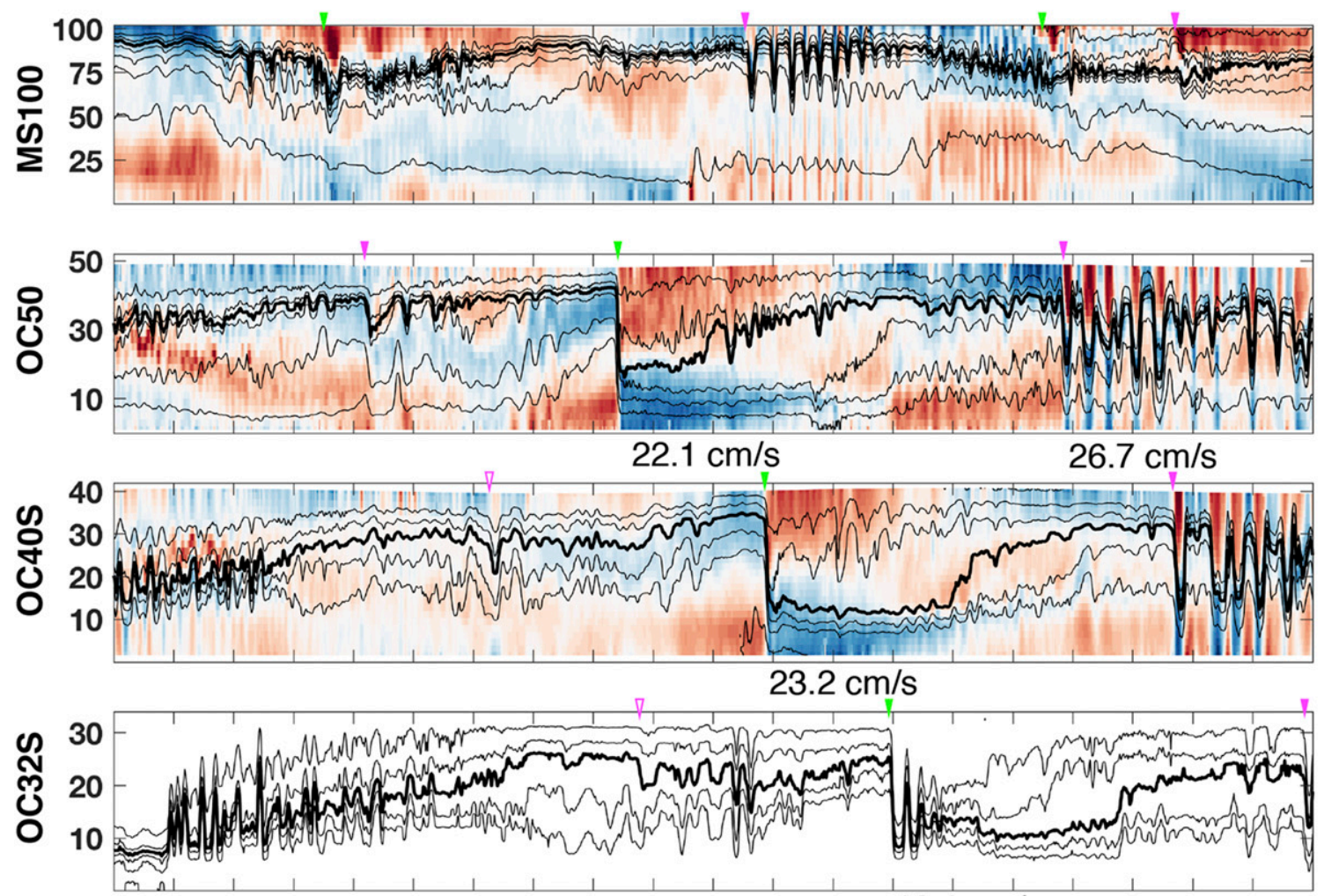

$19.1 \mathrm{~cm} / \mathrm{s}$

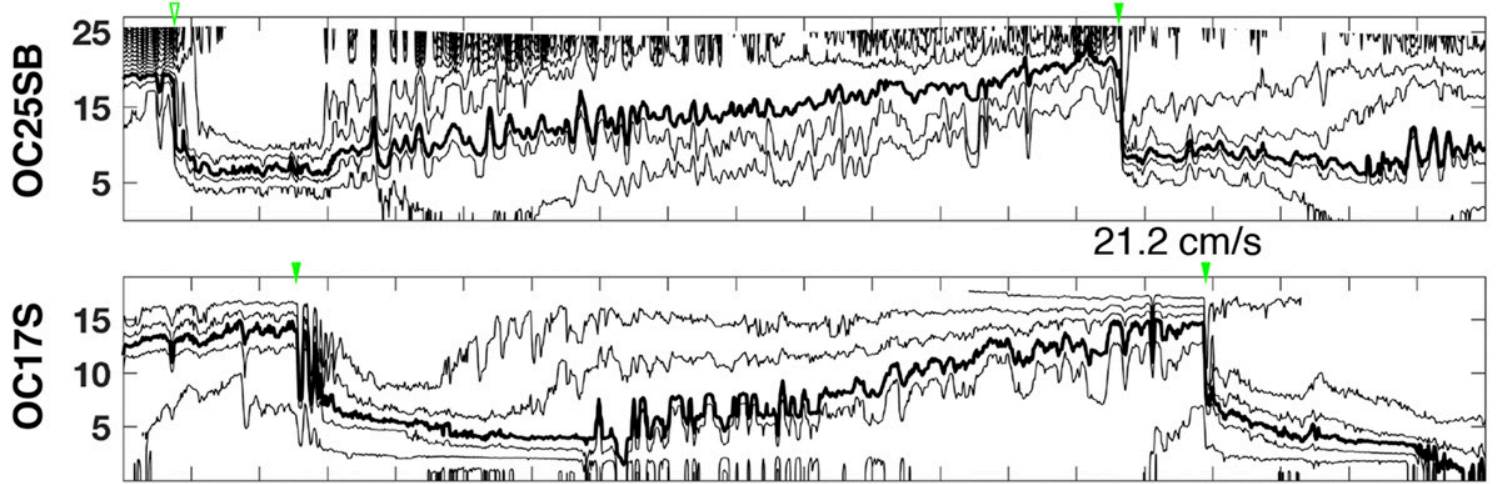

$16.7 \mathrm{~cm} / \mathrm{s}$

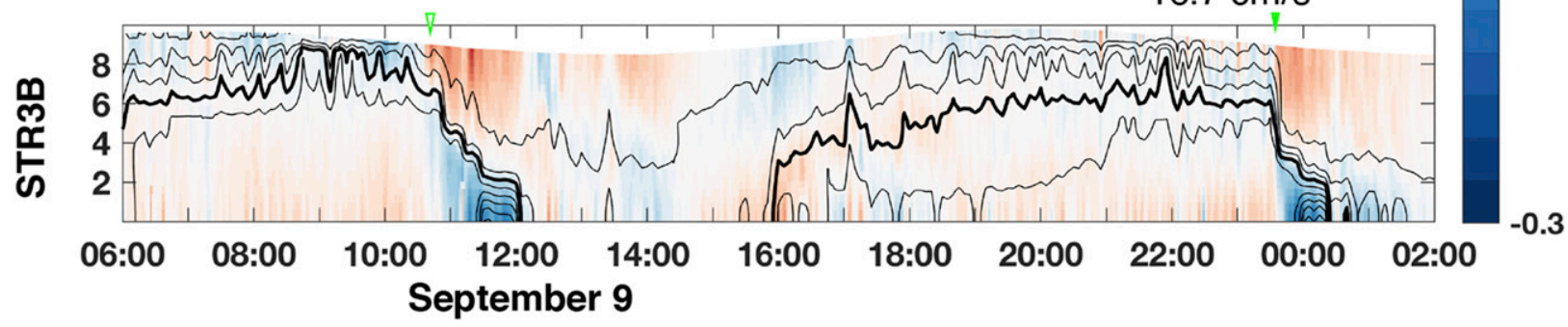

FIG. 4. Eastward velocity colored (3-min-16-h bandpass filtered, with positive values toward east) and temperature contoured (black lines, $1^{\circ}$ contours with the thick contour indicating the $15^{\circ}$ isotherm) from MS100, OC50, OC40S, OC32S, OC25SB, OC17S, and STR3B (from top to bottom in the figure) from 0600 UTC 9 Sep to 0200 UTC 10 Sep 2017. The $y$ axis is meters above the bed. Bore arrivals are indicated by alternating green and magenta triangles, where solid triangles show arrivals that meet the \pm 15 -min certainty threshold and the triangles with a white center do not. Available speed estimates from the triangulation method (Table 2) are shown between panels. 


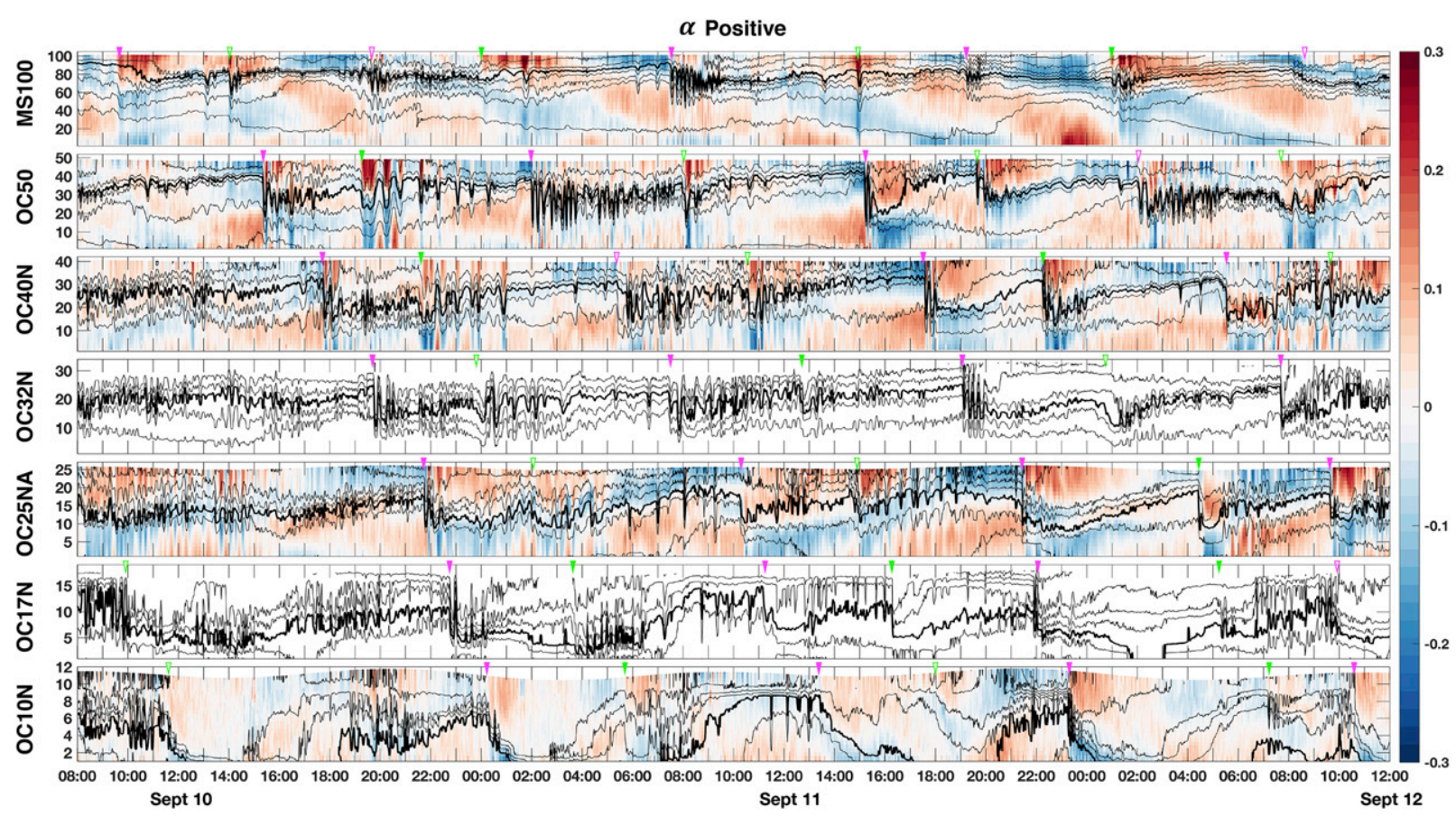

FIG. 5. As in Fig. 4, but for moorings MS100, OC50, OC40N, OC32N, OC25NA, OC17N, and OC10N (from top to bottom in the figure) from 0800 UTC 10 Sep to 1200 UTC 12 Sep 2017.

moorings along with the subtidal wind and the timing of bore arrivals relative to the barotropic tide (Fig. 9). We note that the observational period spans several springneap cycles and roughly seven wind-relaxations. Without distinguishing how these two time scales and physical processes may contribute differently to subtidal variability, we observe a strong subtidal modulation of $\alpha$ over the observational period. The subtidal modulation of $\alpha$ at MS100 is distinct from that at the shallower moorings and will be discussed further in section $4 \mathrm{~b}$.

The cross-shore variability of $\alpha$ is indicative of important cross-shore gradients in the waveguide (Fig. 9e). While $\alpha$ at MS100 is always positive, its sign at the other moorings oscillates. Values of $\alpha$ at OC50 and OC40N are strongly correlated, as are those at OC25NA and OC17N. In general, the magnitude of $\alpha$ decreases from offshore to nearshore, but the oscillations are higher frequency and larger magnitude at the shallowest locations. The differences between OC50/40N and $\mathrm{OC} 25 \mathrm{NA} / 17 \mathrm{~N}$ indicate that these two cross-shore regions are dynamically distinct.

A comparison of the subtidal, offshore wind $(>33 \mathrm{~h})$ and $\alpha$ at the individual moorings confirms that stratification in the nearshore ( $\leq 25-\mathrm{m}$ depth) is highly correlated with wind (Table 4). Lagged negative correlation coefficients between $\alpha$ and subtidal winds are less than 0.05 for the isobaths $40 \mathrm{~m}$ and deeper but are $\sim 0.2-0.28$ for the 25-, 17-, and 10-m isobaths. The time lags range from 1 to $3 \mathrm{~h}$. From the lagged time series comparison of subtidal wind and $-\alpha$ at these shallower moorings, it appears that the nearshore response to changes in the offshore wind is not always consistent (Fig. 10).

Bore-to-bore variability in $\alpha$ is clear from the prearrival estimate, indicating higher-frequency variability of the upstream waveguide (Fig. 8). The pre-arrival $\alpha$ is often larger than that estimated from sorted stratification, which is consistent with observations of the pycnocline upheaving prior to a bore's arrival (Figs. 4 and 5). These nuances illustrate the sensitivity of $\alpha$ to how the background density profile is defined.

\section{d. Internal bore characteristics}

\section{1) QuALITATIVE DIFFERENCES IN THE BORES DURING DIFFERENT SUBTIDAL CONDITIONS}

A first-order question is whether the internal bores are qualitatively different when $\alpha$ is positive, negative, and near zero across the shoaling region. To answer this question, we identify three time periods during which the cross-shore gradient of subtidal $\alpha$ is different (Fig. 9, gray shading): 1) $\alpha$ is positive across the shoaling region, 2) $\alpha$ is positive offshore and negative inshore, and 3) the subtidal $\alpha$ is near zero at locations with $\leq 50-\mathrm{m}$ depth.

Comparing 2-day time series at the northern crossshore mooring transect (Figs. 5, 11, and 12), it is clear that the IW field is distinct during these three periods. 

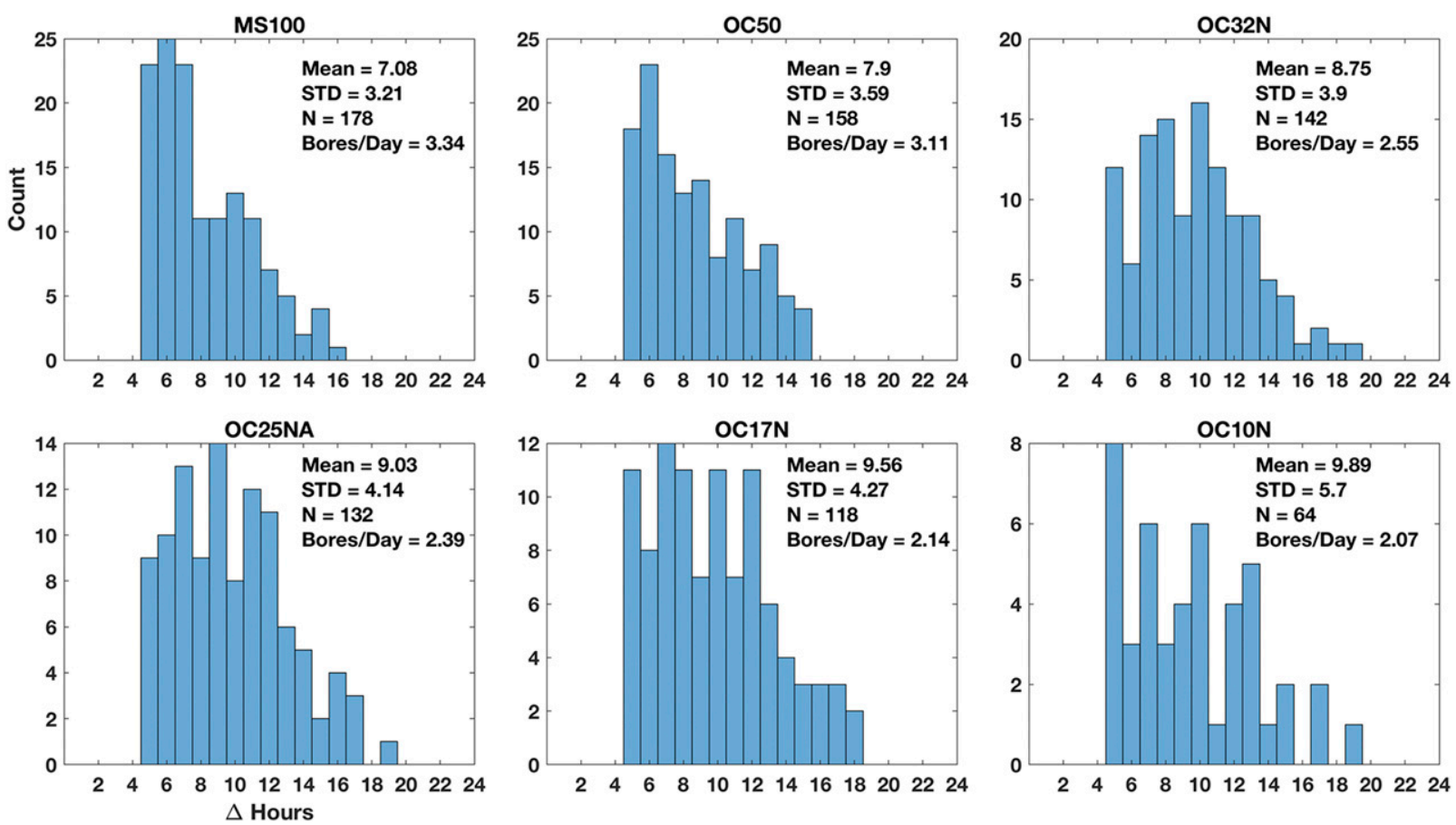

FIG. 6. Histograms of the number of hours between subsequent bores at the MS100, OC50, OC32N, OC25NA, OC17N, and OC10N moorings; $N$ is the number of bores identified at that location [as discussed in section 2b(1)]. For plotting, we exclude points for which $\Delta$ hours is greater than $24 \mathrm{~h}$ (but we include them in the statistics). The statistics shown here are also given in Table 1.

Bores are trackable to shore over the entire observational period (Fig. 9b), but sharp bore fronts are most often observed when $\alpha$ is positive. The depth-averaged semidiurnal kinetic energy $\left(\overline{\mathrm{KE}_{\mathrm{SD}}}\right)$ at each mooring varies within the observational period (Fig. 9c), which also must be considered when comparing the three $\alpha$ regimes. Specifically, at the 100- and 50-m isobaths $\overline{\mathrm{KE}_{\mathrm{SD}}}$ increases over the observational period whereas at the $25-\mathrm{m}$ mooring it decreases from September to October. This implies that cross-shore gradients in $\overline{\mathrm{KE}_{\mathrm{SD}}}$ are changing significantly during the experiment. We focus on linking cross-shore gradients of $\alpha$ to qualitative differences in the internal bore evolution, but will further discuss the waveguide as it relates to kinetic energy in section $4 \mathrm{~b}$.

When $\alpha$ is positive across the shoaling region (Fig. 5), the leading edge of the bores have a sharp front that is sustained across the inner shelf. The bores are easily trackable to shore, and there is little to no rarefication of the bores' leading edge. The bores are large amplitude, and the pycnocline is depressed quickly downward with each bore arrival. After the bore front passes, the pycnocline relaxes relatively slowly to the prebore position. In cases in which the pycnocline is still somewhat depressed when the next bore arrives, the subsequent bore encounters different $\alpha$ conditions and the pre-arrival stratification is likely more important than the subtidal $\alpha$.
The bore fronts are more rarefied when $\alpha$ is negative, leading to increased difficulty tracking them all the way to shore when $\alpha$ nearshore is negative (Fig. 11). Although subtidal $\alpha$ at OC50 is near zero, the pre-arrival $\alpha$ is positive (Fig. 8). This explains why the bores at OC50 look qualitatively similar to the period when $\alpha$ is positive at all locations (Fig. 5). From the 40-m isobath and shallower, there is greater variability in $\alpha$ immediately prior to a bore's arrival which leads a range of bore shapes. For example, at $\mathrm{OC} 32 \mathrm{~N}$ the majority of the bores encounter a negative $\alpha$ and have a rarefied leading edge, but the bore that arrives at 2215 UTC 23 September has a positive upstream $\alpha$ and a sharp leading edge (Fig. 11).

When subtidal $\alpha$ is near zero, we observe the crossshore evolution of bore fronts to vary substantially (Fig. 12). The upstream stratification, which is strongly influenced by the preceding bore, appears to be the main control on whether the bore front rarefies or steepens during the transit onshore. Thus, the prearrival $\alpha$ is of increased importance. We observe bores (such as that observed at $\mathrm{OC} 17 \mathrm{~N}$ at 1325 UTC 24 October) that encounter positive $\alpha$ conditions offshore and negative conditions inshore, thus becoming more rarefied during the transit to shore. We also see examples of $\alpha$ being positive at OC50, near zero or negative at OC32N and OC25NA, and then positive at OC17N. In these instances (such as the bore observed 


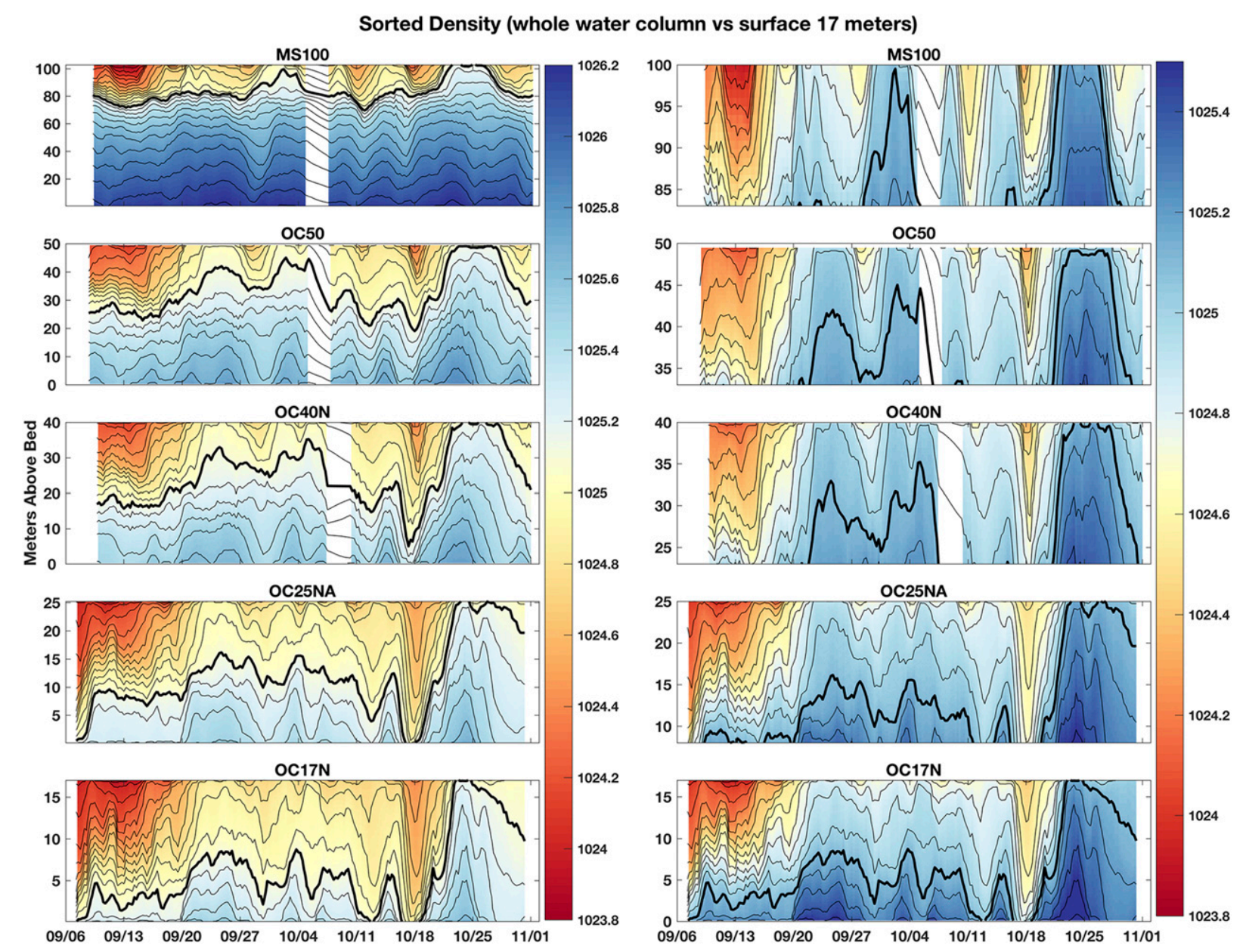

FIG. 7. Sorted density $\left(\mathrm{kg} \mathrm{m}^{-3}\right)$ as described in section $2 \mathrm{~b}(1)$ for the MS100, OC50, OC40N, OC25NA, and OC17N (bottom) moorings (from top to bottom in the figure) for (left) the whole water column and (right) only the topmost $17 \mathrm{~m}$. The $0.1 \mathrm{~kg} \mathrm{~m}^{-3}$ isopycnal intervals are contoured (black lines), and the $1025.1 \mathrm{~kg} \mathrm{~m}^{-3}$ isopycnal is thick. The $y$ axis for all panels is meters above the bed. Temporal gaps occur when moorings were out of the water.

at OC50 at 1800 UTC 23 October), the bore will steepen, rarefy, and then steepen again.

These observations suggest that the subtidal modulation of $\alpha$ may affect how an internal bore evolves during shoaling, but a bore's influence on the waveguide and thus the evolution of the following bore will not be captured by the subtidal waveguide. Within the 2-day windows discussed (Figs. 5, 11, and 12), the values of $\alpha$ estimated from sorted density are fairly constant but the bores do not all evolve similarly. This demonstrates that high-frequency changes in the waveguide, including stratification changes due the bores themselves (Fig. 8), in fact contribute to bore-to-bore variability in shoaling evolution.

\section{2) SPEED}

Linear phase speeds at the northern cross-shore mooring line are subtidally modulated and $c_{o}$ generally decreases from offshore to inshore (Fig. 9d). We compare observed bore speeds with estimates of $c_{o}$ from the sorted and pre-arrival densities (Fig. 13). Since triangle A spans the OC50 and OC40N/S moorings, one would expect the observed speeds to fall within the range of the predictions if the waves were linear. The data suggest, however, that the internal bores at this location are generally slower than $c_{o}$ with the exception of a few cases in October.

Speeds calculated from the sorted and pre-arrival densities capture subtidal changes in bore speed, but fail to predict the observed bore-to-bore variability. The speed estimates from the pre-arrival density do predict some bore-to-bore fluctuations, but they are much smaller than and not well-correlated with observed speeds. For example, we observe that the speed of subsequent bores can vary by $0.05-0.1 \mathrm{~m} \mathrm{~s}^{-1}$, but the estimates from prearrival density vary roughly from 0.02 to $0.05 \mathrm{~m} \mathrm{~s}^{-1}$. 

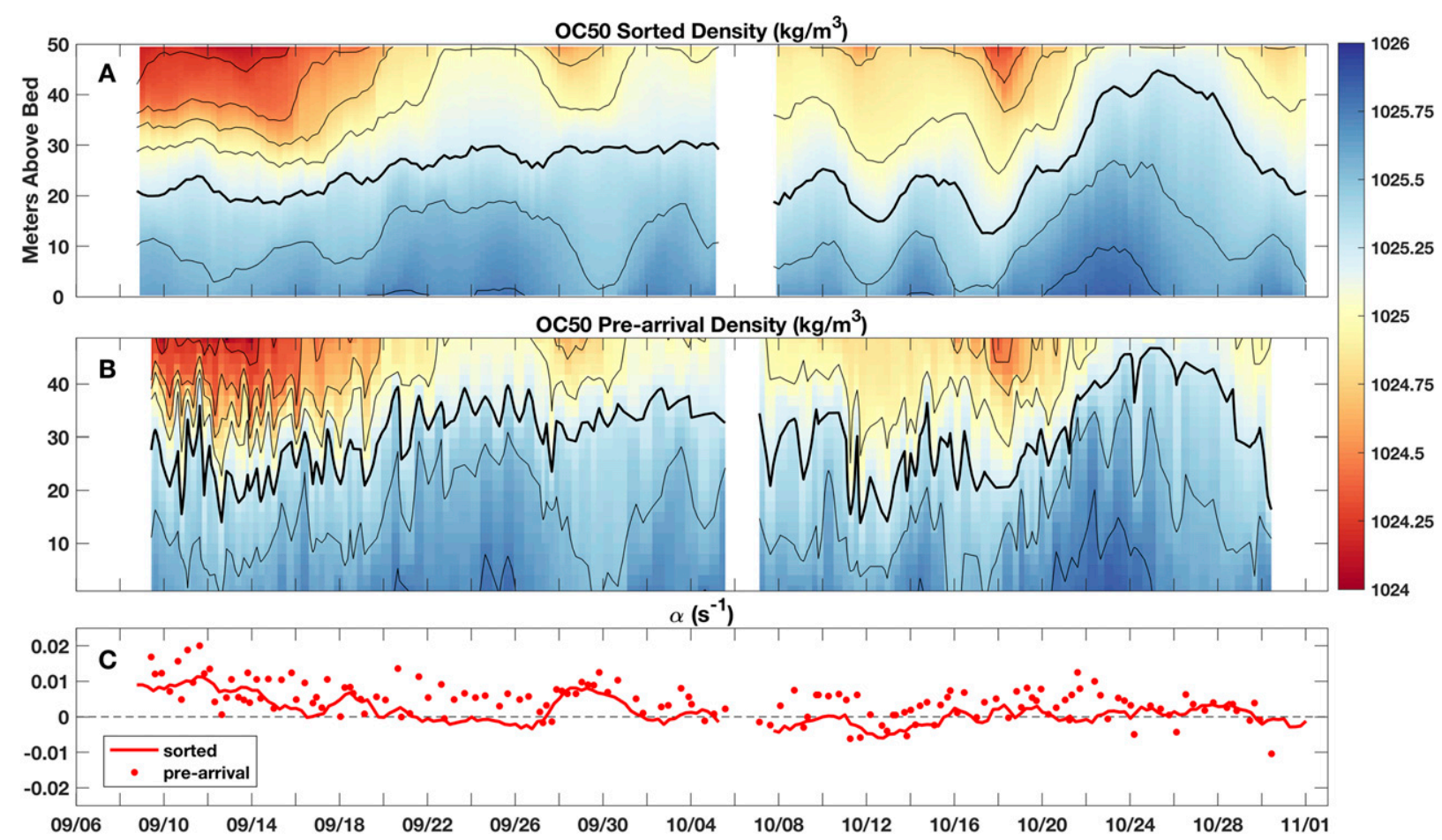

FIG. 8. Comparison of (a) sorted and (b) pre-arrival density $\left(\mathrm{kg} \mathrm{m}^{-3}\right)$ for OC50. The contours denote $0.25 \mathrm{~kg} \mathrm{~m}^{-3}$ isopycnal intervals, and the thick contour is the $1025.25 \mathrm{~kg} \mathrm{~m}^{-3}$ isopycnal. The gap in (b) denotes when the mooring was out of the water. We lose data on the edges of the sorted density because of the sorting method, which is why the gap is wider in (a) than in (b). (c) Corresponding $\alpha$ ( ${ }^{-1}$ ) estimates from the sorted (line) and pre-arrival (dot) densities at OC50 [section 2b(1)].

Based on our error analysis (Fig. 2), observed speed fluctuations (Fig. 13) greater than $0.035 \mathrm{~m} \mathrm{~s}^{-1}$ (black dots) and $0.07 \mathrm{~m} \mathrm{~s}^{-1}$ (gray dots) indicate true bore-to-bore speed variability. Thus, the observed speed fluctuations are larger than the noise, and we can resolve bore-tobore variations in speed. These observations suggest that subtidal and high-frequency processes that modulate waveguide will influence a bore's speed.

\section{3) Propagation direction}

Propagation direction is estimated from the triangulation method based on observed arrival times that meet the \pm 15 -min threshold (Fig. 13). Unlike the observations of speed, there is little bore-to-bore variability in propagation direction. Most of the internal bores propagate from the south, and we estimate about $20 \%$ of them to propagate within $\pm 3.5^{\circ}$ of the shore-normal direction. There appears to be subtidal modulation of the propagation angle, but we do not explore this variability further.

\section{e. Bores propagating into shallow water}

We utilize the entire northern cross-shore mooring transect to describe the cross-shore variability in bore speeds. Comparing the observed bore speeds (Fig. 14, red dots) to the nonrotating, long-wave linear phase speeds $\left(c_{o}\right.$; gray/black dots) and the group velocities including rotation $\left(c_{g}\right.$; light-green dots), there is a clear distinction between the observed and theoretical estimates. Both linear speed estimates predict bores to slow down as they propagate into shallow water, while the data demonstrate that bores maintain a steady speed until about $17 \mathrm{~m}$ isobath. This finding corroborates the survey observations discussed in section 3a (Figs. 3 and 4) and suggests there is a mechanism causing a bore to sustain speed as it transits through the shoaling region.

The observed bore speeds are always faster than the $c_{g}$ estimates and are slower than $c_{o}$ estimates at depths $>$ $32 \mathrm{~m}$ but faster than $c_{o}$ at shallower locations. The range of observed and linear speeds can be fairly large (up to $0.25 \mathrm{~m} \mathrm{~s}^{-1}$ in some locations) due to subtidal changes in the waveguide over the observational period (Figs. 9 and 13). This variability, along with the scarce number of bores that can be tracked to shore with quantitative certainty, makes it difficult to constrain how robust this pattern of maintained bore speed is. A fully nonlinear, nonhydrostatic model that includes rotation would be the best tool to further explore why bores maintain speed during shoaling and assess how common the behavior is. 

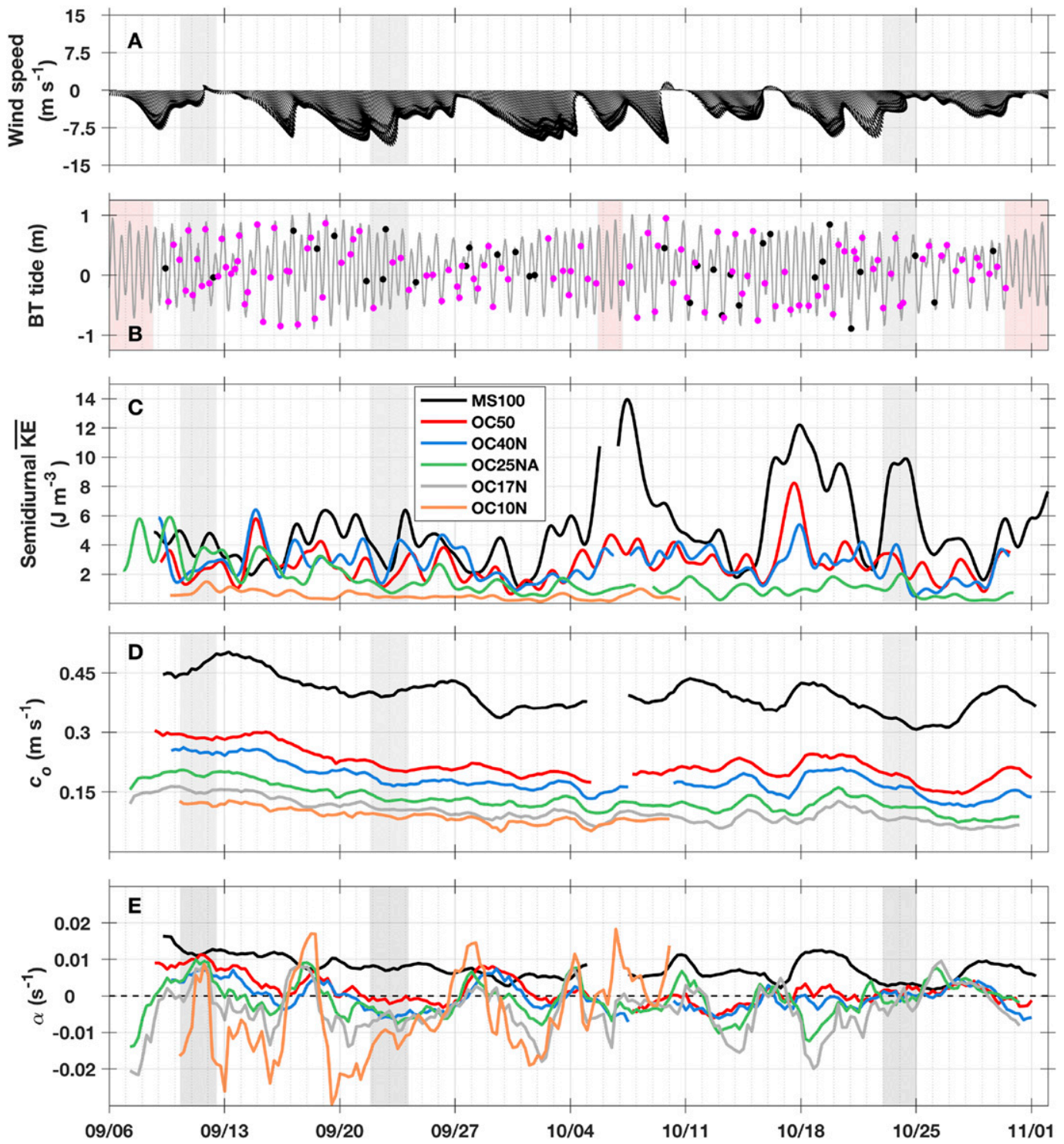

FIG. 9. (a) Low-passed ( $>33 \mathrm{~h}$ ) winds from the Santa Maria buoy offshore of the Oceano mooring array. Wind direction shown is the direction toward which the wind is blowing. (b) The barotropic tide and arrival times of internal bores at MS100 (all dots). Magenta dots indicate bores that can be tracked all the way to OC17N. (c) Depth-averaged kinetic energy $\overline{\mathrm{KE}}$ in the semidiurnal band (1-16-h bandpass filtered) for the cross-shore moorings with available velocity data. For (c) only, the blue line is OC40S and not OC40N. We present OC40S data because the semidiurnal $\overline{\mathrm{KE}}$ at the two 40-m moorings is strongly correlated but the southern location had a longer time series of velocity data. Also shown are (d) the nonrotating longwave linear phase speed of the bores and (e) $\alpha$ at MS100 (black), OC50 (red), OC40N (blue), OC25NA (green), OC17N (gray), and OC10N (orange) calculated from the sorted density. The three gray-shaded times in (a)-(e) indicate representative times when $\alpha$ is positive, negative, or near zero (from left to right, respectively). The red shading in (b) indicates when there were not enough mooring data to track bores.

\section{Discussion}

\section{a. Possible explanations for two bores per semidiurnal period}

Our observation of two bores arriving within a semidiurnal period (Figs. 4-6 and Table 1) is not a typical finding. This pattern has been observed in Georges Bank (Lamb 1994) and the New Jersey shelf (Shroyer et al. 2011), but is it uncommon compared to the majority of observations which show one bore each semidiurnal period (Chereskin 1983; Holloway 1987; Ramp et al. 2004; Scotti et al. 2007; Alford et al. 2010). 
TABLE 4. Negative correlation coefficients for the subtidal wind speed and $\alpha$ at shoaling mooring locations. Lagged correlation statistics are also shown. Time series for statistically significant moorings are shown in Fig. 10.

\begin{tabular}{|c|c|c|c|}
\hline Mooring & $\begin{array}{c}R^{2} \text { between subtidal } \\
\text { wind speed }(>33 \mathrm{~h}) \\
\text { and negative } \alpha\end{array}$ & $\begin{array}{c}\text { Lag } \\
\text { time } \\
(\mathrm{h})\end{array}$ & $\begin{array}{c}R^{2} \text { for lagged } \\
\text { correlation between } \\
\text { subtidal wind speed } \\
(>33 \mathrm{~h}) \text { and negative } \\
\alpha\end{array}$ \\
\hline MS100 & 0.002 & 0 & 0.002 \\
\hline OC50 & 0.048 & 0 & 0.048 \\
\hline OC40N & 0.053 & 0 & 0.053 \\
\hline OC25NA & 0.252 & 3 & 0.278 \\
\hline OC17N & 0.274 & 1 & 0.282 \\
\hline OC10N & 0.186 & 2 & 0.196 \\
\hline
\end{tabular}

The generation mechanism of two bores each semidiurnal period has not been elicited from observations, but a fully nonlinear numerical model of Georges Bank indicates that rotation plays a key role in the formation of the second semidiurnal bore by increasing long-wave dispersion (Lamb 1994). In recent years, fully nonlinear numerical models have further clarified how an internal solitary wave in the presence of rotation will form a secondary, nonlinear IW due to a "decay-rebirth" cycle (Helfrich 2007; Stastna et al. 2009; Grimshaw et al. 2014; Ostrovsky and Helfrich 2019). While rotation itself can facilitate the formation of secondary waves, Grimshaw et al. (2014) additionally showed that a shoaling wave without rotation can induce the formation of a second IW but that rotation is necessary to steepen the secondary wave into a bore. It is likely that the combined effects of rotation and shoaling are responsible for the two semidiurnal bores we observe, but we cannot confirm the role of rotation from our observational analysis.
Data from this region collected in 2015 suggested the presence of only one bore per semidiurnal period (Colosi et al. 2018), so these 2017 data potentially indicate interannual variability of the IW field. Observations from the Oregon shelf have demonstrated the difficulty in discerning the causes of IW interannual variability (Suanda and Barth 2015), and such analysis is beyond the focus of this paper. However, a comparison of the 2015 and 2017 waveguide conditions could be a next step to addressing possible causes of IW variability.

This analysis also raises questions about where the bores originate. Observations of propagation direction suggest the two bores come from a similar location and that the subtidal shelf stratification/circulation may steer propagation (Fig. 13). We are unable to elucidate the bores' generation site from these data, but we speculate that they originate either from separate generation sites offset by a fixed distance or from a single generation site with complex bathymetry. We could not distinguish the two bores by their characteristics-such as shape, speed, or energetics-so these details were not helpful in speculating about their origin. Possible generating mechanisms could be further explored with modeling tools.

\section{b. The influence of stratification variability on bore evolution}

For a more intuitive discussion of the physical implications of $\alpha$ variability, we describe the case of a twolayer system with no background shear:

$$
\alpha=\frac{3}{2} c \frac{h_{1}-h_{2}}{h_{1} h_{2}},
$$

where $h_{1}$ and $h_{2}$ are the thicknesses of the upper and lower layers respectively (Grimshaw et al. 1997). Here, the

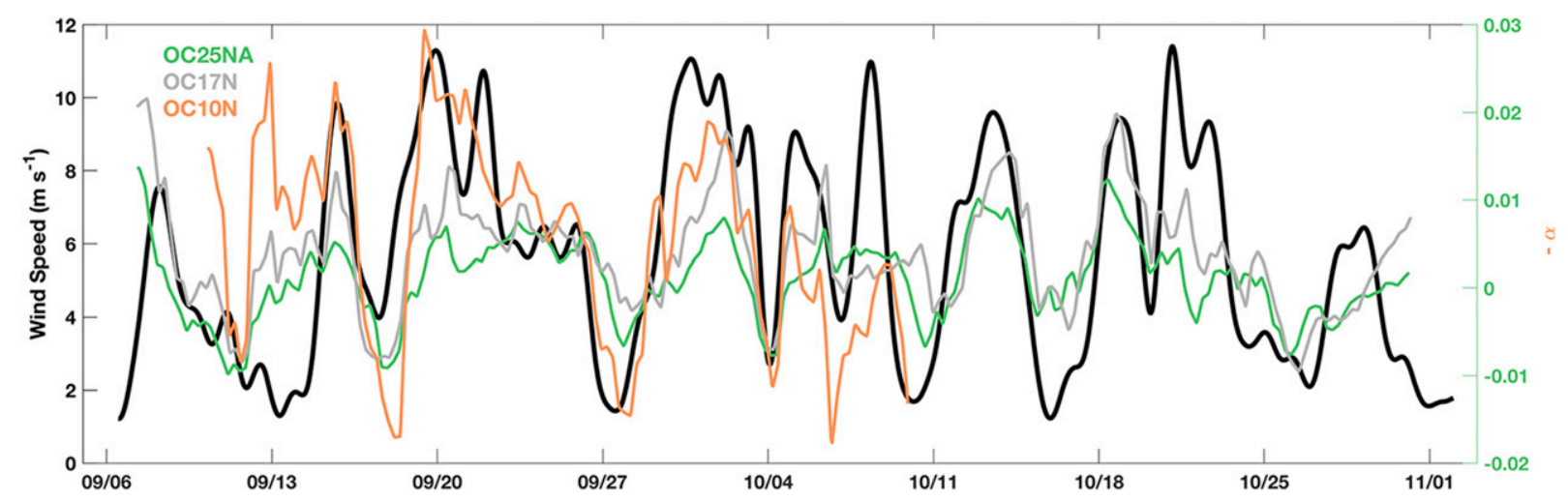

FIG. 10. Time series of subtidal wind speed (left $y$ axis; black) and lagged negative $\alpha$ values (right $y$ axis) at OC25NA (green), OC17N (gray), and OC10N (orange). Lagged correlation coefficients are shown in Table 4. 


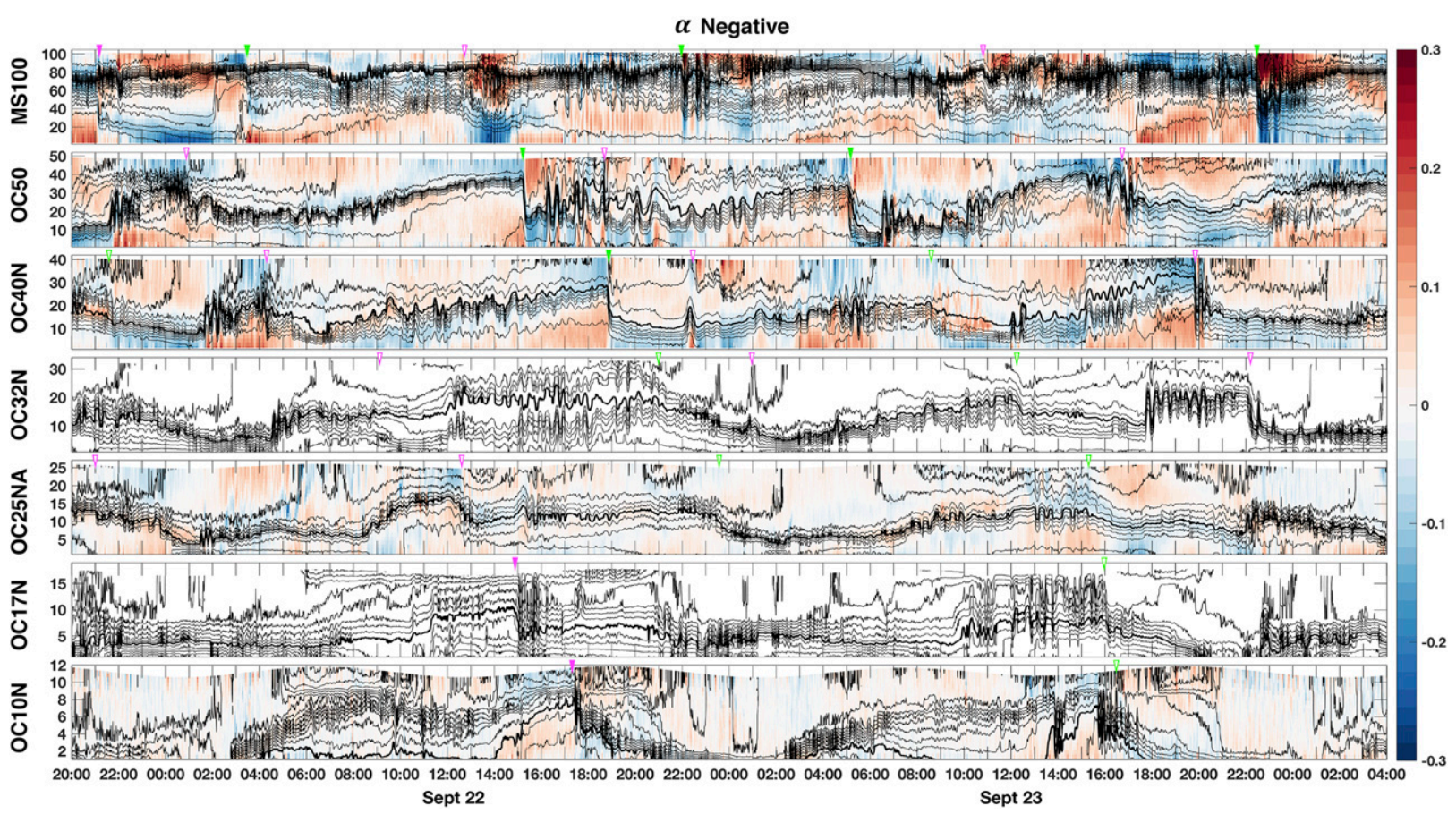

FIG. 11. As in Fig. 5, but from 2000 UTC 21 Sep to 0400 UTC 24 Sep and $0.25^{\circ}$ contours, with the thick line being the $13^{\circ}$ isotherm.

critical depth occurs when $h_{1}=h_{2}$ and thus $\alpha=0$. Offshore where $h_{1}<h_{2}, \alpha$ is positive, but $\alpha$ becomes negative onshore of the critical depth when $h_{1}>h_{2}$. The exact location of the critical depth varies for each IW because of changes in background stratification, but our analysis indicates that it is located between the
32- and 17-m isobaths in our study region-where we frequently observe changes in steepness of the bores' leading edge.

As a bore approaches and passes through the critical depth, its leading edge may either rarefy or steepen depending on its amplitude and the upstream conditions

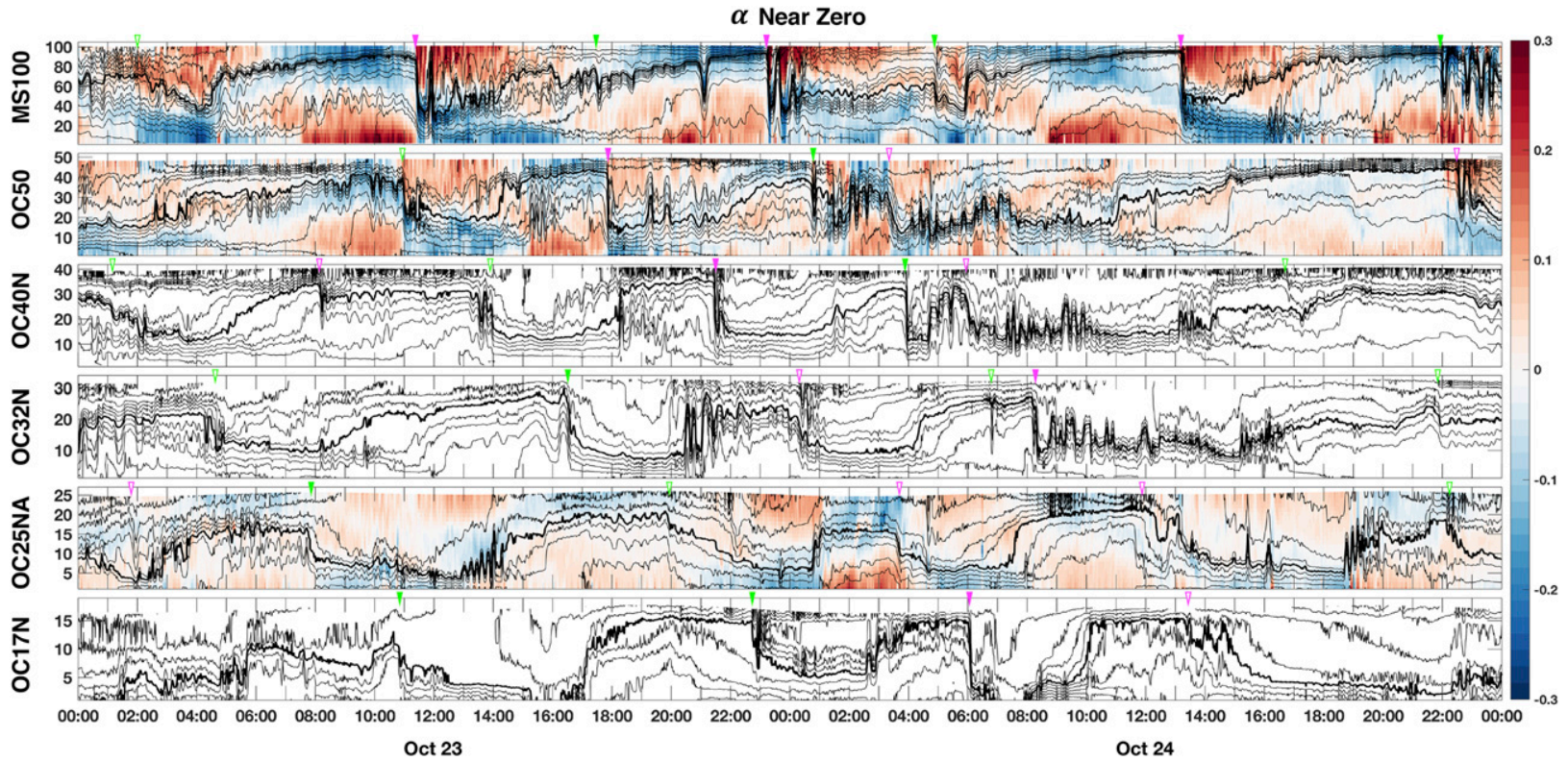

FIG. 12. As in Fig. 5, but from 0000 UTC 23 Oct to 0000 UTC 25 Oct and $0.25^{\circ}$ contours, with the thick line being the $12^{\circ}$ isotherm. OC10N was already recovered, so there are no data there. 


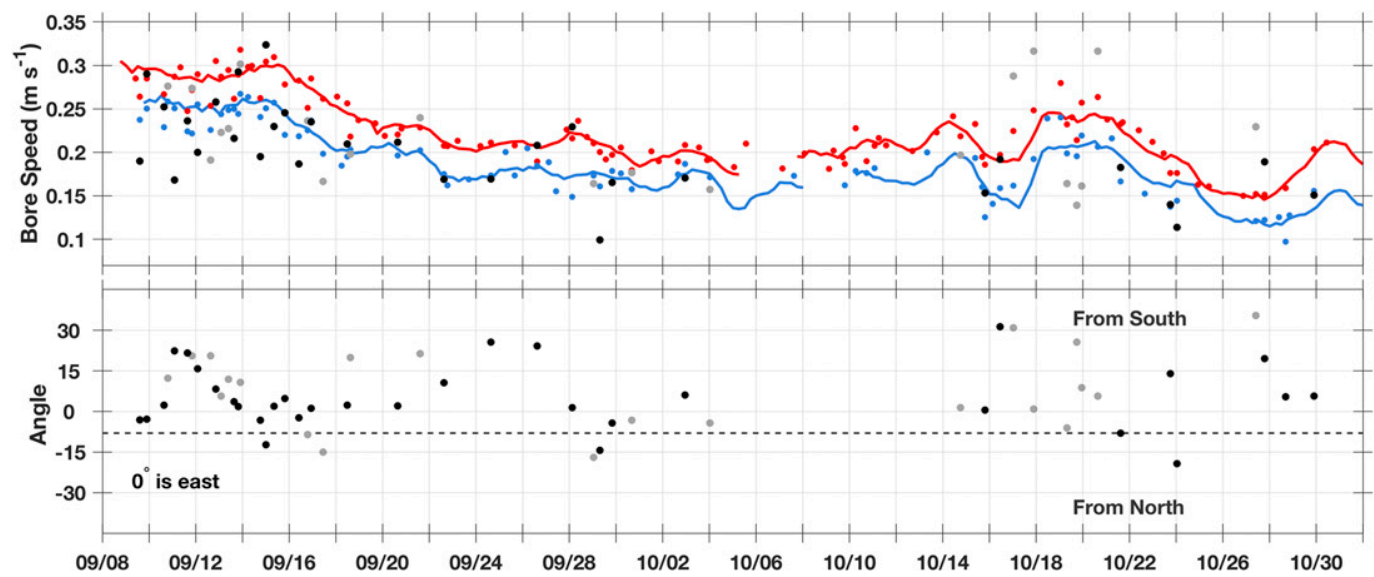

FIG. 13. (top) Speeds estimated at triangle A (Fig. 1) from the arrival times at OC50, OC40N, and OC40S (black and gray dots). Black dots indicate tracked bores that meet the \pm 7.5 -min certainty threshold, and gray dots indicate that the \pm 15 -min certainty criterion is met. The observed bore speeds are corrected for background currents using the barotropic currents projected in the direction of propagation, with corrections ranging from -0.06 to $0.05 \mathrm{~m} \mathrm{~s}^{-1}$. Nonrotating hydrostatic long-wave linear phase speeds are calculated at OC50 (red) and OC40N (blue) moorings from the sorted (colored lines) and the pre-arrival (colored dots) densities. (bottom) Propagation direction of bores estimated from the triangulation method [section $2 \mathrm{~b}(3)$ ] from triangle $\mathrm{A} ; 0^{\circ}$ is due east, positive values indicate northward propagation, and the black dashed line indicates the approximate shore-normal direction $\left(-8^{\circ}\right)$.

(Scotti et al. 2008). Thinking about the two-layer system (Scotti et al. 2008; Baines 1998), the speed along characteristics can be described as

$$
c=\sqrt{g^{\prime}\left(\frac{h_{1} h_{2}}{h_{1}+h_{2}}\right)} .
$$

In this framework, it is evident that the speed is maximal when $h_{1}=h_{2}$. If $h_{1}<h_{2}$ and $\alpha$ is positive, the top of the wave is slower-moving than the bottom and the front will steepen. If $h_{1}>h_{2}$ and $\alpha$ is negative, the top of the wave moves faster than the bottom and the front consequently rarefies, resulting in a less-steep bore. Consistent with this theoretical framework, we observe that the bore fronts remain sharp when $\alpha$ is positive across the entire shoaling region (Fig. 5). When the upstream $\alpha$ is negative, the bore fronts continue to rarefy (Fig. 11). We observe several instances of a bore transitioning from a sharp front to a more rarefied front when $\alpha$ is positive offshore and negative inshore (Fig. 12). There are also cases where $\alpha$ fluctuates from positive to negative to positive, causing the bore front to rarefy and then resteepen (Fig. 12).

Our analysis connects the cross-shore evolution of internal bores to waveguide variability. While the waveguide is modulated by subtidal processes, such as wind-driven mixing and relaxations of the coastal current (Figs. 7 and 9), there is also high-frequency variability driven by the bores themselves (Figs. 5 and 8). We demonstrate that these subtidal and high-frequency changes in stratification (Fig. 8) both influence a bore's cross-shore evolution
(Fig. 5) and speed (Fig. 13). For example, even during periods when the subtidal waveguide is fairly constant (Fig. 9), subsequent bores do not evolve consistently (Figs. 5, 11, and 12) or propagate at the same speed (Fig. 13). We conclude that especially in a region with two semidiurnal bores, bore-to-bore variability in shoaling evolution is likely driven by a confluence of factors, including a bore's impact on the waveguide of the next bore and stratification variability due to the wind (Fig. 10).

Our findings corroborate Holloway et al.'s (1997) conclusion that $\alpha$ 's high-frequency variability plays a key role in determining a bore's transformation during shoaling. Comparing the temporal variability of $\alpha$ across the shoaling region, we note that values are correlated at $50 / 40$ and $25 / 17 \mathrm{~m}$ (Fig. 9). While $\alpha$ at the 100 isobath is subtidally modulated but always positive, $\alpha$ at $50 / 40 \mathrm{~m}$ is subtidally modulated and fluctuates between positive and negative values. At the 25/17- and 10-m isobaths, $\alpha$ has higher-frequency and larger-magnitude fluctuations. Synthesizing this information with the offshore subtidal wind correlations (Fig. 10, Table 4), the effect of stratification on $\alpha$ (Fig. 8), and a bore's influence on the stratification ahead of the subsequent bore (Figs. 5, 11, and 12), we conclude that the cross-shore gradient in $\alpha$ can evolve substantially in the timeframe a bore is propagating onshore. This will affect how a bore's leading edge will evolve across the inner shelf.

While the $100 \mathrm{~m}$ mooring has a muted response to wind relaxations, the locations $<25 \mathrm{~m}$ experience quick $(<1$ day) changes in stratification and $\alpha$ after a relaxation 

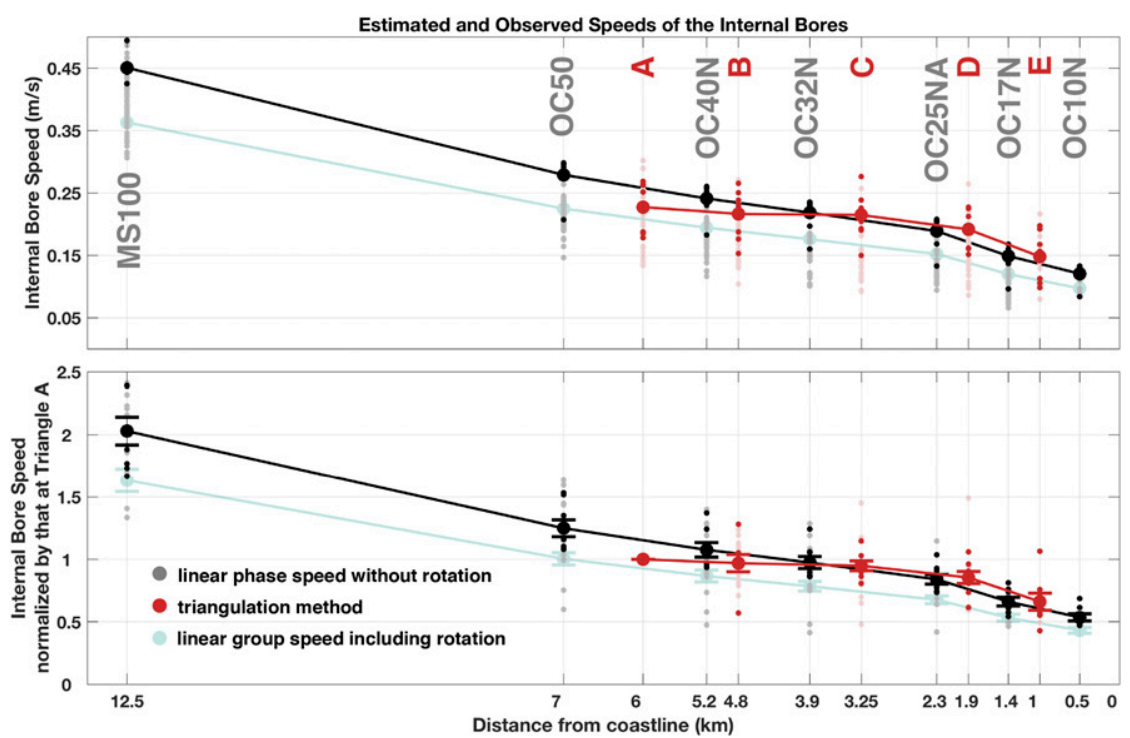

FIG. 14. (top) Nonrotating hydrostatic long-wave linear phase speeds $c_{o}$ estimated from the sorted density at the northern mooring line (gray/black), group velocities $c_{g}$ for the rotating case with an $M_{2}$ frequency estimated from the same moorings (light green), and observed bores speeds calculated from the triangulation method (red) as a function of cross-shore distance. Only estimates for bores that are flagged by the \pm 7.5 -min certainty threshold are included (smaller light dots, excluding $c_{g}$ ), so the number of data points varies at each cross-shore location. Small dark dots indicate the eight instances in which there is a speed estimate at all triangle/rectangle locations (Fig. 1). The average of these eight cases is shown by larger dark dots. To simplify the plot, we only show the averages for $c_{g}$. (bottom) As in the top panel, but all speeds are normalized by the speed at triangle A $(6 \mathrm{~km})$. The horizontal lines indicate \pm 1 standard error for the eight bores tracked with \pm 7.5 -min certainty at each triangle/rectangle location. The across-shelf distance is measured from the blue dot in Fig. 1.

event. The impact of offshore, subtidal winds on nearshore stratification in this region has been shown to have important along- and cross-shore variability (Aristizábal et al. 2017; Melton et al. 2009), but its impact on the waveguide is an open research topic. Our observations suggest that regional, subtidal winds contribute to modulation of the cross-shore waveguide, but it is unclear what the spatial footprint of this is or if local winds are comparably important.

Temporal waveguide changes and internal bore evolution over our observational period appear to be disconnected from variability in the semidiurnal kinetic energy density. For example, $\alpha$ and $c_{o}$ appear to have lower-frequency modulation than the depth-averaged semidiurnal kinetic energy. Comparing the September and October data, we do not observe any changes in the IW field but there is significant shift in the cross-shore kinetic energy gradient. In October, there is more kinetic energy at MS100 and less at OC25NA, meaning that in the latter half of the record there is a larger kinetic energy loss across the shoaling region. We presume that this kinetic energy loss could be associated with stronger dissipation or IW breaking, but are unable to confirm this.

\section{c. Observations versus theory}

The observed bore speeds are always faster than $c_{g}$ estimates and are generally slower than $c_{o}$ offshore of the $32-\mathrm{m}$ isobath and faster than $c_{o}$ farther inshore (Fig. 14). Several studies have suggested that rotation must be accounted for when calculating the speed of an internal bore (Grimshaw et al. 1998; Grimshaw and Helfrich 2012; Colosi et al. 2018) and that the group velocity is the appropriate calculation [Eq. (5)]. However, given the time scales associated with sharp bore fronts (from a few minutes to $1.5 \mathrm{~h}$ ) and the presence an $M_{2}$ bore every $6 \mathrm{~h}$, it is not obvious that a semidiurnal frequency is appropriate to use in calculating $c_{g}$. Consistent with findings by Lamb (1994), we demonstrate that at the semidiurnal frequency, $c_{g}$ estimates are slower than $c_{o}$ by $0.04-0.10 \mathrm{~m} \mathrm{~s}^{-1}$. The nonrotating long-wave phase speed $c_{o}$ has been used for comparison with observations in similar analyses (Lamb 1994; Grimshaw et al. 2004; Shroyer et al. 2011; Thomas 
et al. 2016) and has a cross-shore pattern that is comparable to that of $c_{g}$. The impacts of rotation on bore speeds remain an open research question, which we cannot thoroughly address in this analysis.

Both linear speed estimates predict that the bores slow down as they transit into shallower water, but observations indicate the bores maintain a steady speed over most of the shoaling region (Figs. 3, 4, and 14) and begin to decelerate between the 17- and 10-m isobaths. We cannot elucidate from this dataset the reason that the bores maintain their speed during shoaling and suggest that a fully nonlinear model with rotation would be best to further explore the mechanisms that control a shoaling bore's speed.

Subtidal changes in stratification appear to modulate bore speeds, but there is additional bore-to-bore speed variability whose magnitude and timing are not explained by the upstream stratification (Fig. 13). One possible explanation is that neither the pre-arrival nor sorted densities are representative of the waveguide in a region dominated by 2 semidiurnal internal tides. Comparing our data with observations from regions with only one observed bore per semidiurnal period (Holloway et al. 1997; Scotti et al. 2008; Thomas et al. 2016), it appears that bore-to-bore interactions may facilitate more nonlinear feedbacks when the pycnocline has not yet relaxed to its background position before the arrival of the next bore. The shape/evolution of the internal bores we observe are similar to published observations, but the previous internal bore appears to be a stronger influence here. This is also consistent with numerical work by Lamb and Warn-Varnas (2015), which demonstrated that an IW may influence the upstream conditions ahead of a subsequent wave and that the local upstream profile of the second wave (i.e., the profile trailing the first wave) is a good indicator of the second wave's amplitude/shape.

Our exclusion of background current in calculations of $c_{o}$ and $\alpha$ allows us to better understand how stratification influences the shoaling bores, but there are consequently open questions related to the importance of local shear that should be addressed in further work. One motivating factor to exclude shear was the sensitivity of the wave properties to how the "background shear" was defined and the uncertainty, especially given the presence of bores every $\sim 6 \mathrm{~h}$, regarding the appropriate definition. Local upstream conditions can look quite different from a time-averaged or low-passed profile (Lamb and Warn-Varnas 2015), and the vertical structure of the horizontal shear profile determines how strongly wave properties are influenced by the background current (Stastna and Lamb 2002). Thus, it is possible that bore-to-bore changes in the shear contribute to the unexplained linear bore speed variability.

\section{Conclusions}

We observe two tidal bores arrive every semidiurnal period; of the total, $72 \%$ can be tracked from the $100-\mathrm{m}$ isobath to the 10-m isobath. These large-amplitude bores propagate from roughly the same direction and are offset by $\sim 6 \mathrm{~h}$. The bore speeds are subtidally modulated, but there is additional bore-to-bore speed variability (as large as $10 \mathrm{~cm} \mathrm{~s}^{-1}$ ) that is not explained by the stratification immediately upstream of the bores. It remains an open question what dynamics drive these observed bore-tobore speed fluctuations. Measured bore speeds are always faster than the linear rotating group velocities and are generally slower than the linear longwave nonrotating phase speeds $c_{o}$ offshore of the $32-\mathrm{m}$ isobath and faster than $c_{o}$ farther inshore. Contrary to both linear speed estimates, which predict bores to slow while transiting into shallower depths, the bores maintain a steady speed over most of the shoaling region and start to slow only between 17 and $10 \mathrm{~m}$.

The waveguide, including stratification and $c_{o}$, varies across the shoaling region and evolves over the observational period. We use $\alpha$ as a metric to describe stratification, and generally $\alpha$ is always positive offshore $(\sim 100 \mathrm{~m})$ and more variable inshore. We observe that the critical depth, where $\alpha$ changes sign, is located between the 32- and 17-m isobaths for the majority of the bores. Lagged correlation analyses between subtidal $\alpha$ at each mooring and the subtidal, offshore winds reveal that stratification in the shallower region $(<25 \mathrm{~m})$ is impacted by wind changes while the deeper region $(>40 \mathrm{~m})$ has a muted response. In addition to modulation of the waveguide by subtidal processes, such as wind-driven mixing, upwelling and downwelling, and relaxations of the coastal current, there is also higherfrequency variability of the waveguide driven by the bores themselves. Each bore modifies the conditions the subsequent bore propagates through and, given that the bore itself evolves during shoaling, this can contribute to strong cross-shore gradients in the waveguide on short time scales $(<6 \mathrm{~h})$. Since there are two bores per semidiurnal period in this region, the influence of the bores on the waveguide is especially important compared to other regions where only one bore per semidiurnal period has been observed.

The steepness of a bore's leading edge depends on the upstream waveguide, and we demonstrated that the cross-shore evolution of a bore is determined by the cross-shore gradient of $\alpha$. The bore fronts are steep when $\alpha$ ahead of the bore is positive and are more 
rarefied when the upstream $\alpha$ is near zero or negative. In the case of $\alpha$ being positive offshore and negative inshore, we observe the bore's leading edge to decrease in steepness while shoaling. However, due to the high-frequency fluctuations in $\alpha$ caused by the bores themselves, there are also instances in which $\alpha$ is negative/near zero offshore compared to inshore. In these cases, the rarefied leading edge of the wave resteepens into a sharp bore. Because high-frequency changes in the waveguide are so important in this region, there can be significant bore-to-bore variability in the cross-shore evolution of the bores during similar subtidal waveguide conditions.

Our observations demonstrated that the coastal waveguide has complex spatiotemporal variability modulating the evolution of shoaling internal bores. These findings suggest that mixing on the inner shelf, which depends on how/when/where internal waves break, will also be influenced by variability of cross-shore gradients in the waveguide.

Acknowledgments. We thank the personnel who helped on the R/V Oceanus and R/V Sally Ride during mooring operations and surveying. Funding was provided by the Office of Naval Research Inner Shelf Departmental Research Initiative (Grants N00014-15-12617, N00014-15-1-2466, N00014-15-1-2870, N00014-151-2633, N00014-19WX00588). Data on the project scale are in the process of being archived, but data presented in this paper can be immediately accessed by contacting Dr. Jacqueline McSweeney at jmcsweeney@coas. oregonstate.edu.

\section{REFERENCES}

Alford, M. H., R.-C. Lien, H. Simmons, J. Klymak, S. Ramp, Y. J. Yang, D. Tang, and M.-H. Chang, 2010: Speed and evolution of nonlinear internal waves transiting the South China Sea. J. Phys. Oceanogr., 40, 1338-1355, https://doi.org/10.1175/ 2010JPO4388.1.

Apel, J. R., 2003: A new analytical model for internal solitons in the ocean. J. Phys. Oceanogr., 33, 2247-2269, https://doi.org/ 10.1175/1520-0485(2003)033<2247:ANAMFI > 2.0.CO;2.

Aristizábal, M. F., M. R. Fewings, and L. Washburn, 2017: Effects of the relaxation of upwelling-favorable winds on the diurnal and semidiurnal water temperature fluctuations in the Santa Barbara Channel, California. J. Geophys. Res. Oceans, 122, 7958-7977, https://doi.org/10.1002/2017JC013199.

Baines, P. G., 1998: Topographic Effects in Stratified Flows. Cambridge University Press, 500 pp.

Cairns, J. L., 1967: Asymmetry of internal tidal waves in shallow coastal waters. J. Geophys. Res., 72, 3563-3565, https://doi.org/ 10.1029/JZ072i014p03563.

Chereskin, T. K., 1983: Generation of internal waves in Massachusetts Bay. J. Geophys. Res., 88, 2649-2661, https://doi.org/ 10.1029/JC088iC04p02649.
Colosi, J. A., N. Kumar, S. H. Suanda, T. M. Freismuth, and J. H. MacMahan, 2018: Statistics of internal tide bores and internal solitary waves observed on the inner continental shelf off Point Sal, California. J. Phys. Oceanogr., 48, 123-143, https:// doi.org/10.1175/JPO-D-17-0045.1.

Grimshaw, R., and K. Helfrich, 2012: The effect of rotation on internal solitary waves. IMA J. Appl. Math., 77, 326-339, https:// doi.org/10.1093/imamat/hxs024.

_ de Vries equation in the theory of large-amplitude internal waves. Nonlinear Processes Geophys., 4, 237-250, https://doi.org/10.5194/ npg-4-237-1997.

, L. A. Ostrovsky, V. I. Shrira, and Y. A. Stepanyants, 1998: Long nonlinear surface and internal gravity waves in a rotating ocean. Surv. Geophys., 19, 289-338, https://doi.org/10.1023/ A:1006587919935.

—_, E. Pelinovsky, and O. Poloukhina, 2002: Higher-order Korteweg-de Vries models for internal solitary waves in a stratified shear flow with a free surface. Nonlinear Processes Geophys., 9, 221-235, https://doi.org/10.5194/npg-9-221-2002.

,-- T. Talipova, and A. Kurkin, 2004: Simulation of the transformation of internal solitary waves on oceanic shelves. J. Phys. Oceanogr., 34, 2774-2791, https://doi.org/10.1175/ JPO2652.1.

- C. Guo, K. Helfrich, and V. Vlasenko, 2014: Combined effect of rotation and topography on shoaling oceanic internal solitary waves. J. Phys. Oceanogr., 44, 1116-1132, https://doi.org/ 10.1175/JPO-D-13-0194.1.

Helfrich, K. R., 2007: Decay and return of internal solitary waves with rotation. Phys. Fluids, 19, 026601, https://doi.org/10.1063/ 1.2472509 .

_, W. K. Melville, and J. Miles, 1984: On interfacial solitary waves over slowly varying topography. J. Fluid Mech., 149, 305-317, https://doi.org/10.1017/S0022112084002664.

Henyey, F. S., and A. Hoering, 1997: Energetics of borelike internal waves. J. Geophys. Res., 102, 3323-3330, https://doi.org/ 10.1029/96JC03558.

Holloway, P. E., 1987: Internal hydraulic jumps and solitons at a shelf break region on the Australian North West Shelf. J. Geophys. Res., 92, 5405-5416, https://doi.org/10.1029/ JC092iC05p05405.

_ E. Pelinovsky, T. Talipova, and B. Barnes, 1997: A nonlinear model of internal tide transformation on the Australian North West Shelf. J. Phys. Oceanogr., 27, 871-896, https://doi.org/ 10.1175/1520-0485(1997)027<0871:ANMOIT>2.0.CO;2.

Lamb, K. G., 1994: Numerical experiments of internal wave generation by strong tidal flow across a finite amplitude bank edge. J. Geophys. Res., 99, 843-864, https://doi.org/10.1029/ 93JC02514.

_ 2002: A numerical investigation of solitary internal waves with trapped cores formed via shoaling. J. Fluid Mech., 451, 109-144, https://doi.org/10.1017/S002211200100636X.

_ - and L. Yan, 1996: The evolution of internal wave undular bores: Comparisons of a fully nonlinear numerical model with weakly nonlinear theory. J. Phys. Oceanogr., 26, 2712-2734, https:// doi.org/10.1175/1520-0485(1996)026<2712:TEOIWU >2.0.CO;2.

— simulations of shoaling internal solitary waves at the ASIAEX site in the South China Sea. Nonlinear Processes Geophys., 22, 289-312, https://doi.org/10.5194/npg-22-289-2015.

Lee, C., and R. C. Beardsley, 1974: The generation of long nonlinear internal waves in a weakly stratified shear flow. J. Geophys. Res., 79, 453-462, https://doi.org/10.1029/JC079i003p00453. 
Lee, O. S., 1961: Observations on internal waves in shallow water. Limnol. Oceanogr., 6, 312-321, https://doi.org/10.4319/ lo.1961.6.3.0312.

Lerczak, J. A., C. D. Winant, and M. C. Hendershott, 2003: Observations of the semidiurnal internal tide on the southern California slope and shelf. J. Geophys. Res., 108, 3068, https:// doi.org/10.1029/2001JC001128.

— surf meets coastal ocean. Eos, Trans. Amer. Geophys. Union, 100, https://doi.org/10.1029/2019EO122141.

Li, Q., and D. M. Farmer, 2011: The generation and evolution of nonlinear internal waves in the deep basin of the South China Sea.J. Phys. Oceanogr., 41, 1345-1363, https://doi.org/10.1175/ 2011JPO4587.1.

Melton, C., L. Washburn, and C. Gotschalk, 2009: Wind relaxations and poleward flow events in a coastal upwelling system on the central California coast. J. Geophys. Res., 114, C11016, https:// doi.org/10.1029/2009JC005397.

Moum, J. N., D. M. Farmer, W. D. Smyth, L. Armi, and S. Vagle, 2003: Structure and generation of turbulence at interfaces strained by internal solitary waves propagating shoreward over the continental shelf. J. Phys. Oceanogr., 33, 2093-2112, https://doi.org/ 10.1175/1520-0485(2003)033<2093:SAGOTA > 2.0.CO;2.

Ostrovsky, L. A., and K. R. Helfrich, 2019: Some new aspects of the joint effect of rotation and topography on internal solitary waves. J. Phys. Oceanogr., 49, 1639-1649, https://doi.org/ 10.1175/JPO-D-18-0154.1.

Perry, R. B., and G. R. Schimke, 1965: Large-amplitude internal waves observed off the northwest coast of Sumatra. J. Geophys. Res., 70, 2319-2324, https://doi.org/10.1029/JZ070i010p02319.

Pineda, J., 1991: Predictable upwelling and the shoreward transport of planktonic larvae by internal tidal bores. Science, 253, 548549, https://doi.org/10.1126/SCIENCE.253.5019.548.

_ 1999: Circulation and larval distribution in internal tidal bore warm fronts. Limnol. Oceanogr., 44, 1400-1414, https://doi.org/ 10.4319/lo.1999.44.6.1400.

Ramp, S. R., and Coauthors, 2004: Internal solitons in the northeastern South China Sea. Part I: Sources and deep water propagation. IEEE J. Oceanic Eng., 29, 1157-1181, https:// doi.org/10.1109/JOE.2004.840839.

Scotti, A., and J. Pineda, 2004: Observation of very large and steep internal waves of elevation near the Massachusetts coast. Geophys. Res. Lett., 31, L22307, https://doi.org/10.1029/ 2004GL021052.

B. Butman, R. C. Beardsley, P. S. Alexander, and S. Anderson, 2005: A modified beam-to-earth transformation to measure short-wavelength internal waves with an acoustic Doppler current profiler. J. Atmos. Oceanic Technol., 22, 583591, https://doi.org/10.1175/JTECH1731.1.
- R. C. Beardsley, and B. Butman, 2007: Generation and propagation of nonlinear internal waves in Massachusetts Bay. J. Geophys. Res., 112, C10001, https://doi.org/10.1029/ 2007JC004313.

,,$---\frac{1}{-}$, and J. Pineda, 2008: Shoaling of nonlinear internal waves in Massachusetts Bay. J. Geophys. Res., 113, C08031, https://doi.org/10.1029/2008JC004726.

Shroyer, E. L., J. N. Moum, and J. D. Nash, 2009: Observations of polarity reversal in shoaling nonlinear internal waves. J. Phys. Oceanogr., 39, 691-701, https://doi.org/10.1175/2008JPO3953.1. , and _- 2010: Energy transformations and dissipation of nonlinear internal waves over New Jersey's continental shelf. Nonlinear Processes Geophys., 17, 345-360, https://doi.org/10.5194/npg-17-345-2010.

$\_, \ldots$, and $\_, 2011$ : Nonlinear internal waves over New Jersey's continental shelf. J. Geophys. Res., 116, C03022, https://doi.org/10.1029/2010JC006332.

Stanton, T. P., and L. A. Ostrovsky, 1998: Observations of highly nonlinear internal solitons over the continental shelf. Geophys. Res. Lett., 25, 2695-2698, https://doi.org/10.1029/98GL01772.

Stastna, M., and K. G. Lamb, 2002: Large fully nonlinear internal solitary waves: The effect of background current. Phys. Fluids, 14, 2987-2999, https://doi.org/10.1063/1.1496510.

_ F. J. Poulin, K. L. Rowe, and C. Subich, 2009: On fully nonlinear, vertically trapped wave packets in a stratified fluid on the f-plane. Phys. Fluids, 21, 106604, https://doi.org/10.1063/1.3253400.

Suanda, S. H., and J. A. Barth, 2015: Semidiurnal baroclinic tides on the central Oregon inner shelf. J. Phys. Oceanogr., 45, 2640-2659, https://doi.org/10.1175/JPO-D-14-0198.1.

Thomas, J. A., J. A. Lerczak, and J. N. Moum, 2016: Horizontal variability of high-frequency nonlinear internal waves in Massachusetts Bay detected by an array of seafloor pressure sensors. J. Geophys. Res. Oceans, 121, 5587-5607, https:// doi.org/10.1002/2016JC011866.

Vlasenko, V., and K. Hutter, 2002: Numerical experiments on the breaking of solitary internal waves over a slope-shelf topography. J. Phys. Oceanogr., 32, 1779-1793, https://doi.org/ 10.1175/1520-0485(2002)032<1779:NEOTBO>2.0.CO;2.

— , and N. Stashchuk, 2007: Three-dimensional shoaling of largeamplitude internal waves. J. Geophys. Res., 112, C11018, https://doi.org/10.1029/2007JC004107.

Walter, R. K., C. B. Woodson, R. S. Arthur, O. B. Fringer, and S. G. Monismith, 2012: Nearshore internal bores and turbulent mixing in southern Monterey Bay. J. Geophys. Res., 117, C07017, https://doi.org/10.1029/2012JC008115.

Winters, K. B., P. N. Lombard, J. J. Riley, and E. A. D'Asaro, 1995: Available potential energy and mixing in density-stratified fluids. J. Fluid Mech., 289, 115-128, https://doi.org/10.1017/ S002211209500125X. 